Document downloaded from:

http://hdl.handle.net/10251/179431

This paper must be cited as:

Micó, JC.; Amigó, S.; Caselles, A.; Romero, PD. (2021). Biology and personality: a mathematical approach to the body-mind problem. Kybernetes. 50(5):1566-1587. https://doi.org/10.1108/K-03-2020-0138

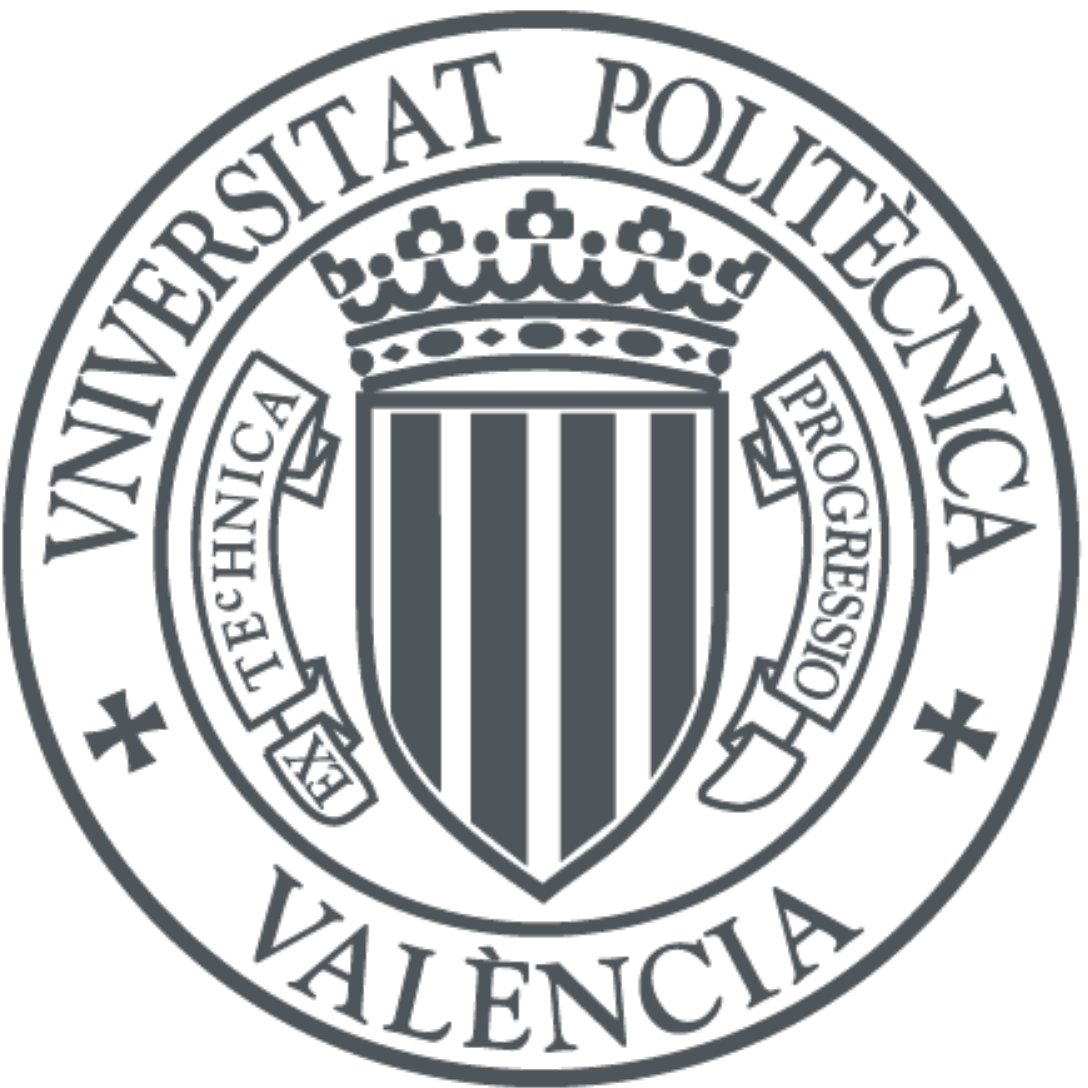

The final publication is available at

https://doi.org/10.1108/K-03-2020-0138

Copyright Emerald

Additional Information 


\section{Biology and personality: a mathematical approach to the body-mind problem}

\begin{tabular}{|r|l|}
\hline Journal: & Kybernetes \\
\hline Manuscript ID & K-03-2020-0138.R1 \\
\hline Manuscript Type: & Research Paper \\
\hline Keywords: & $\begin{array}{l}\text { body-mind problem, general factor of personality, response model, } \\
\text { integro-differential equation; , bridge model, second order partial } \\
\text { differential equation }\end{array}$ \\
\hline \multicolumn{2}{|l}{} \\
\hline
\end{tabular}

\section{SCHOLARONE ${ }^{\text {M }}$ Manuscripts}




\title{
Biology and personality: a mathematical approach to the body-mind problem
}

\author{
Joan C. Micó a, Salvador Amigó ${ }^{b}$, Antonio Caselles ${ }^{c}$, Pantaleón D. Romero ${ }^{\text {d* }}$ \\ ${ }^{a}$ Institut Universitari de Matemàtica Multidisciplinar, Universitat Politècnica de València, Camí de Vera s/n, 46022 \\ València, Spain \\ b Departament de Personalitat, Avaluació i Tractaments Psicològics. Universitat de València, Av. Blasco Ibáñez 21, \\ 46010. València, Spain. \\ c IASCYS member. Departament de Matemàtica Aplicada, Universitat de València (retired), Dr. Moliner 50, 46100 \\ Burjassot, Spain. ESI \\ dESI International Chair@CEU-UCH. Departamento de Matemáticas, Física y Ciencias Tecnológicas. Carrer San \\ Bartolomé 55, 46115 Alfara del Patriarca (Valencia), Spain.
}

\begin{abstract}
Purpose - The purpose of this paper is to investigate the body-mind problem from a mathematical invariance principle in relation to personality dynamics in the psychological and the biological levels of description.

Design/methodology/approach - The relationship between the two mentioned levels of description is provided by two mathematical models: the response model and the bridge model. The response model (an integro-differential equation) is capable to reproduce the personality dynamics as a consequence of a determined stimulus. The invariance principle asserts that the response model can reproduce personality dynamics at the two levels of description. The bridge model (a second order partial differential equation) can be deduced as a consequence of this principle: it provides the co-evolution of the General Factor of Personality (GFP) (mind), the c-fos and DRD3 gens, and the glutamate neurotransmitter (body).

Findings - An application case is presented by setting up two experimental designs: a previous pilot AB pseudoexperimental design with one subject and a subsequent $\mathrm{ABC}$ experimental design with another subject. The stimulus used is the stimulant drug Methylphenidate (MPD). The response and bridge models are validated with the outcomes of these experiments.

Originality/value - The mathematical approach here presented is based on a holistic personality model developed in the last few years: the Unique Trait Personality Theory, which claims for a single personality trait to understand the overall human personality: the GFP.
\end{abstract}

Keywords: body-mind problem; general factor of personality; response model; integro-differential equation; bridge model; second order partial differential equation; c-fos; DRD3; glutamate; methylphenidate.

\section{Introduction}

The objective of this paper is to provide a mathematical approach to the body-mind problem based on a holistic personality model developed in the last few years: the Unique Trait Personality Theory (UTPT) [1, 2]. The UTPT claims for a unique trait, as synonymous of single

\footnotetext{
${ }^{*}$ Corresponding author.

E-mail addresses: jmico@mat.upv.es (J.C. Micó); salvador.amigo@uv.es (S. Amigó); antonio.caselles@uv.es (A. Caselles); pantaleon.romero@uchceu.es (Pantaleón D. Romero);
} 
trait, to understand the overall human personality. The concept "unique trait" is substituted latter by the equivalent concept of General Factor of Personality (GFP) in the reference [2], in order to follow the generally accepted term by the scientific community.

The studies about the central concept of GFP proposed by the UTPT define a new, emergent and novel field inside personality research. It treats about "the single general factor hypothesis" and proposes a general factor of personality within the Big Five Factors (B5F) model (the five factors are: Extraversion, Responsibility, Neuroticism, Openness to Experience and Agreeableness), occupying the GFP the apex of the hierarchy of personality factors $[3,4,5,6,7$, 8, 9, 10, 11, 12, 13]. The Five-Adjective Scale of the General Factor of Personality (GFP-FAS) $[14,15]$ offers the possibility to measure the dynamical change of the GFP in a single individual, due to its strong correlation with the GFP questionnaire [2]. The GFP-FAS is a dynamically observable instrument to measure the GFP. Such an instrument is essential for validating the here presented dynamical mathematical approach to the body-mind problem.

In addition, the GFP has a physiological base, given by the general activation of the stress system (general activation, GA, for short). The GA is also particularly asserted as representing the brain activation level when it is particularized to the GA in brain [2, 16]. Moreover, two kinds of GA can be distinguished depending on the conditions acting on the stress system: the tonic GA (the state of the GA in absence of stimuli), and the phasic GA (the dynamic response of the GA as a consequence of one or more stimuli). Both the psychological level of description, given by the GFP, and its corresponding physiological level of description, given by the GA, can change along time as a consequence of a stimulus.

The biological level of description has to be taken into account for an overall personality description. This biological level is constituted by the biochemical indicators related to personality and their dynamical interrelationships. The three biochemical indicators considered in this paper are the regulator gens c-fos and DRD3, and the neurotransmitter glutamate. They have been chosen due to their close relationship with personality, such as the following paragraphs try to demonstrate.

The scientific literature shows a close relationship between personality and c-fos expression. Take into account that c-fos expression is considerably increased in the brain's regions involved in the regulation of arousal states; regions such as the locus coeruleus (noradrenergic neurons) and the medial preoptic area (non-GABAergic neurons) [24]. In [22] it is demonstrated that the response model is capable to reproduce the joint dynamics of the immediate-early gen c-fos (body) and the GFP (mind) as a consequence of a Methylphenidate (MPD) dose and suggests the need to deepen into this relationship from a mathematical approach.

There is also a close relationship between personality and DRD3 expression. For instance, DRD3 is considered to play a major role in cognition and emotion [25], in neuropsychiatric diseases [26], and in personality [27]. Furthermore, there is evidence that DRD3 plays a role in addiction mechanisms, such as drug-seeking and drug-taking behavior [28, 29]. In fact, reference [30] demonstrates that the MPD and the self-regulation therapy produces changes in the GFP (mind) and in the DRD3 expression (body), such as it happens in the experimental designs of [2], which brings us again the need to deepen into this relationship from a mathematical approach.

Besides, glutamate is not only a neurotransmitter. Glutamate has regulatory functions in immune-component cells and in nervous system. Glutamate is an indicator of the organism's general state of activation, and thus of the GFP. In fact, the joint dynamics of glutamate and the 
GFP has been successfully described with the response model as a consequence of a methylphenidate dose in [31]. Reference [31] demonstrates again the need to deepen into this relationship from a mathematical approach.

The use of MPD as the stimulus considered in the application case presented here is suitable. Actually, such as the works $[32,33]$ demonstrate, a previous dopamine deficit in brain favors a greater increase of dopamine in brain in response to a dose of MPD [1]. Note that the increase of dopamine in brain is equivalent to an increase of the general activation, and thus of the GFP.

The here presented response model is an integro-differential equation that is a generalization of the model presented in [16]. It has been validated in [21] when the stimulus is caffeine and in [22] when the stimulus is MPD. The model reproduces accurately the dynamic patterns of the brain activation as a consequence of a stimulant drug intake, such as it is predicted by the works $[17,18,19,20]$. These works predict a general dynamic pattern given by an inverted U-shape, but other exceptional patterns can also be observed, such as: an inverted-U followed by a recovering $\mathrm{U}$; a decaying $\mathrm{U}$ from the beginning up to the end of the experimental period; or a growth that tends to maintain a constant value along the experimental period. In addition, the generalized response model is the here used one to reproduce the respective dynamics of the GFP, the c-fos, the DRD3 and the glutamate, as a consequence of a MPD dose intake.

An important assumption when relating mathematically the psychological level of description (mind) with the biological level of description (body) is the invariance principle. It asserts that the response model has to use the same mathematical structure to describe both dynamics: that of the GFP (mind) and that of the biochemical indicators related to personality (body) (c-fos, DRD3 and glutamate). As a consequence of the invariance principle, the so-called bridge model (a second order partial differential equation) can be deduced. The bridge model provides the coevolution or dynamical relationship between every biochemical indicator and the GFP along time (through its time dependence on the stimulus).

Two previous versions of the bridge model have also been used in personality theory $[34,35]$. However, the here deduced bridge model version presents a theoretical advance respect to the ones presented in [34, 35]. On a hand, the bridge model proposed in [35] relates the Big Five Factors (B5F) with the GFP and time. It has the restriction that no inhibitor delay (see Section 2, for the meaning of this term) is present in the simplified version of the response model that the authors applied to both the GFP and the B5F dynamics. Its validation takes place in the context of an experimental design where the participants consumed caffeine. In that case, the deduced bridge model is a first order partial differential equation that relates every component of the B5F with the GFP and time. On the other hand, the referred inhibitor delay is considered in [12] to develop a first mathematical approach about the body-mind problem by using another bridge model: a set of two coupled first order partial differential equations relating c-fos and glutamate with the GFP response and time. Its validation takes place in the context of an experimental design where the participants consumed methylphenidate. However, despite its generality, obtained by including the inhibitor delay term, that model produces in some cases artificial singularities due to the difficulty to state precise boundary conditions, which makes difficult to handle it numerically. The bridge model proposed in the present paper reformulates the two coupled partial differential equations as a second order partial differential equation, on which two boundary conditions are precisely formulated and no singularities are observed, which makes easier to handle it numerically. 
In the following paragraphs the body-mind problem is described from a historical and a philosophical point of view, trying to put the presented mathematical approach in the context of some theoretical frames proposed in that view.

Reference [36] presents a good summary of this problem in the history of knowledge: the first rational approach to the body-mind problem is attributed to Plato as a dualism between sensitive (body) and intelligible (mind) worlds. Aristotle substitutes Plato's dualism by a matter-shape dualism, considering in his approach psychology (in the early ages of philosophy) as a part of physiology. In the Middle Ages the Christian dualism between body and soul (mind) is the dominant thought. Descartes defends a substantial dualism of body and mind but connected through the pineal glandule, although Spinoza and Leibnitz reduce the dualism to two aspects of an all, rather than two totally separated aspects. In the twentieth century positivism proposes association as a way to study the relationship between body and mind through the scientific method.

At the beginning of the 20th century, Wittgenstein, as opposed to the dualism body-mind, defends that people do not know phenomena by their physical manifestations, but by their behavior [37]. In fact, Wittgenstein defends that behavior is the actual expression of mind. This idea is supported as well by the dominant behaviorist psychology [36] of the 20th and 21st centuries, which maintains that only behavior can be object of scientific study.

Neuroscience has made possible the search for more global explanations for the mind-body problem, reframing it as a mind-brain problem with the neuroplasticity concept [38]. Also with the help of Psychoimmunology [39, 40] the scientific study of the relationship between body and mind is better understood. Both works emphasize that the negative consequence of the mentioned interaction can be found in the general activation of the stress system at long term. Due to the close relationship between the GFP and the general activation, the use of a stimulusresponse model (the response model) is supported by the two last cited works.

Basically, ending the twentieth century and starting the twenty-first century, two philosophers of science have studied deeply the body-mind problem: Karl R. Popper [41] and Mario Bunge [42]. Popper's work tackles the problem with the theory of the three worlds. Following Motterlini's review [43] of Popper's work: "world 1 is the realm of physical bodies and their physical and physiological states; world 2, of mental states; and world 3, of the products of the human mind, such as theories, languages, arguments, works of art, and generally all the objective contents of thought". In system language, world 1, world 2 and world 3 are three interrelated subsystems that have arisen hierarchically as a consequence of the biological evolution. However, the early Luecken's review work [44] criticizes the absence of concretion in the definition of Popper's worlds. Despite the absence of concretion, also shared by Ben \& Chaim [45], this work emphasizes the fact that learning takes place in world 3, being its dynamics of a stimulus-response kind. As a hypothesis, the here presented response model would describe a general feature (GFP) of the world 2 in Popper's context, and its biological indicators (c-fos, DRD3 and glutamate) in world 1, being the bridge model, in world 3, the relationship between world 1 and world 2.

Bunge's work [42] points out that there are three general trends to understand the body-mind problem: neural, holistic and systemic. The neural and holistic trends, following Bunge, are not the most suitable ones to solve the body-mind problem. He presents a dynamic network model of the central nervous system that relates subsystems represented by different sets of neurons 
(neuron assemblies). The obtained theoretical results must be contrasted with the experimental ones with the observation of representative biological data, such as the blood flow in the different subsystems. Observe that the here presented approach is, using Bunge's terminology, rather holistic; it would measure the GFP with the response model, as related with the general activation of the stress system, but not presenting comparable results between the different subsystems by the moment. However, neither experimental designs describing the dynamics of the biological indicators nor relationships between personality and biological indicators are presented in Bunge's approach, such as it is done in this paper.

An interesting work about the so denominated the neuron approach by Bunge is the one of Gold \& Stoljar [46]: they offer a defense and description of the interdisciplinary neuron approaches to solve the body-mind problem; and present some open peer commentaries and the corresponding Gold \& Stoljar's answers. The open peer commentary done by Zanker [47] stresses that: "a more clearly defined experimental paradigm seems necessary to solve this exciting and substantial problem". The work by Agassi [48] revises as well the different approaches but insisting again in the need to perform testable explanations. Haken's theory of Synergetics [49] and its application to brain functioning and cognition responds to Bunge's neuron trend by searching the wave dynamic patterns from the lighthouse model of neuron.

Other works such as those of Brearley [50] and Scalzone [51] postulate the dialogue between psychoanalysis and neuroscience based on the assumption that both deal with virtual structures, without stating any mathematical approximation but proposing a common qualitative language between neurons and behavior. The work of Basar \& Guntekin [52] attempts to approach the problem from the quantum physics and chaos theory, but it is just a set of intentions rather than a stated model to solve the body-mind problem. The same comments can be done about the work of Dvoryanchikova, Delamer \& Martinez [53] that attempts to provide some tries to focus the problem from the structure of intelligent systems.

This paper is organized as follows. In Section 2 the response model is presented and explained. In Section 3 the bridge model is deduced from the response model through the invariance principle. Section 4 is devoted to present the experimental designs. The results obtained from them are used to validate the response model for the GFP and the biological indicators (c-fos, DRD3, and glutamate) in Section 5, and to validate the bridge model in Section 6. The conclusions of the work are presented in Section 7, together with the paper discussion.

\section{The response model}

The response model is the mathematical tool used to compute the short term dynamics of the GFP as a result of a stimulus produced by a single dose intake of a drug, such as it has been used in $[16,21,22,31,34,35]$. Let us recall the response model in the following paragraphs.

Assuming that no drug is present in the organism before consuming it, the stimulus time dependence $s(t)$, i.e., the amount of drug in the organism not yet consumed (or metabolized) by cells at time $t$, is provided by the function:

$$
s(t)=\left\{\begin{array}{c}
\frac{\alpha \cdot M}{\beta-\alpha}(\exp (-\alpha \cdot t)-\exp (-\beta \cdot t)): \alpha \neq \beta \\
\alpha \cdot M \cdot t \cdot \exp (-\alpha \cdot t): \alpha=\beta
\end{array}\right.
$$


In Eq. $1, M$ is the initial amount of a drug single dose, $\alpha$ is the drug assimilation rate, and $\beta$ is the stimulus elimination rate.

The dynamics of the GFP is given by the following equation:

$$
\left.\begin{array}{c}
\frac{d y(t)}{d t}=a(b-y(t))+\frac{p}{b} s(t)-b \cdot q \cdot \int_{0}^{t} \mathrm{e}^{\frac{x-t}{\tau}} \cdot s(x) \cdot y(x) d x \\
y(0)=y_{0}
\end{array}\right\}
$$

Eqs. 1 and 2 represent the response model. In Eq. 2, $s(t)$ represents the stimulus given by Eq. $1 ; y(t)$ represents the GFP dynamics; and $b$ and $y_{0}$ are respectively its tonic level and its initial value. The dynamics of Eq. 2 is a balance of three terms, which provide the time derivative of the GFP: the homeostatic control $(a(b-y(t)))$, i.e., the cause of the fast recovering of the tonic level $b$, the excitation effect $(p \cdot s(t) / b)$, which tends to increase the GFP, and the inhibitor effect $\left(\int_{0}^{t} \mathrm{e}^{\frac{x-t}{\tau}} \cdot s(x) \cdot y(x) d x\right)$, which tends to decrease the GFP and is the cause of a continuously delayed recovering, with the weight $\mathrm{e}^{\frac{x-t}{\tau}}$. Parameters $a, p, q$ and $\tau$ are named respectively the homeostatic control power, the excitation effect power, the inhibitor effect power and the inhibitor effect delay. All the parameters of the model depend on the individual personality or individual biology and on the type of stimulus. The correct interpretation of the tonic level $b$ is important to be stressed: its value is situational and depends on the individual and the kind of stimulus. The response model provided such as Eq. 2 is fundamental to deduce the bridge model.

Besides, Eq. 2 can be transformed into a system of two coupled differential equations. To do this, let us define the $z(t)$ variable as:

$$
z(t)=\int_{0}^{t} \mathrm{e}^{\frac{x-t}{\tau}} \cdot s(x) \cdot y(x) d x=\mathrm{e}^{-\frac{t}{\tau}} \int_{0}^{t} \mathrm{e}^{\frac{x}{\tau}} \cdot s(x) \cdot y(x) d x
$$

Then, by taking the time derivative of $z(t)$ we obtain:

$$
\begin{gathered}
\left.\frac{d y(t)}{d t}=\begin{array}{c}
a(b-y(t))+\frac{p}{b} s(t)-b \cdot q \cdot z(t) \\
y(0)=y_{0}
\end{array}\right\} \\
\left.\begin{array}{c}
\frac{d z(t)}{d t}=-\frac{z(t)}{\tau}+s(t) \cdot y(t) \\
z(0)=0
\end{array}\right\}
\end{gathered}
$$

Eqs. 1, 4 and 5 define a mathematical structure of the response model equivalent to that given by Eqs. 1 and 2, and they are used to obtain its numerical solutions in an easy way.

\section{The bridge model}

In order to deduce the bridge model, the starting point is assuming the invariance principle, i.e., the dynamical response of every biological indicator can be also described by the response model, but with different parameter values. Thus, let us call $E_{i}$ to each one of the three biological indicators, with $1 \leq i \leq 3: E_{1} \equiv C$ (c-fos), $E_{2} \equiv D$ (DRD3) and $E_{3} \equiv G$ (glutamate). In addition, 
if $E_{l}^{(0)}$ is the corresponding initial value in $t=0$, and $A_{i}, B_{i}, P_{i}, Q_{i}$ and $T_{i}$ are the corresponding parameters, the response model corresponding to the biological indicators can be written as:

$$
\left.\begin{array}{c}
\frac{d E_{i}(t)}{d t}=A_{i}\left(B_{i}-E_{i}(t)\right)+\frac{P_{i}}{B_{i}} S(t)-B_{i} \cdot Q_{i} \cdot \int_{0}^{t} \mathrm{e}^{\frac{x-t}{T_{i}}} \cdot s(x) \cdot E_{i}(x) d x \\
E_{i}(0)=E_{i}^{(0)}
\end{array}\right\}
$$

Note that $1 \leq i \leq 3$ in Eq. 6. From now onwards the subscripts will hold this meaning. In addition, note also that $s(t)$ is the stimulus function, i.e., it is the same as in Eq. 1, which means that it is the same for the three biological indicators and for the GFP. The invariance principle assumes that the influence of the stimulus on the three biological indicators and on the GFP is the same. Therefore, from this hypothesis, $s(t)$ only depends on the individual biology and on the kind of stimulus. As a consequence, $\alpha$ (assimilation rate) and $\beta$ (elimination rate) have the same value for the three biological indicators and for the GFP.

Note again that with the change specified in the following equation:

$$
F_{i}(t)=\int_{0}^{t} \mathrm{e}^{\frac{x-t}{T_{i}}} \cdot s(x) \cdot E_{i}(x) d x=\mathrm{e}^{-\frac{t}{T_{i}}} \int_{0}^{t} \mathrm{e}^{\frac{x}{T_{i}}} \cdot S(x) \cdot E_{i}(x) d x
$$

Eq. 6 becomes a system of two coupled differential equations:

$$
\left.\begin{array}{c}
\frac{d E_{i}(t)}{d t}=A_{i}\left(B_{i}-E_{i}(t)\right)+\frac{P_{i}}{B_{i}} S(t)-B_{i} \cdot Q_{i} \cdot F_{i}(t) \\
E_{i}(0)=E_{i}^{(0)}
\end{array}\right\}
$$

Eqs. 8 and 9 constitute a mathematical structure of the response model equivalent to that given by Eq. 6, and they are used to obtain its numerical solutions in an easy way.

To find the mathematical relationship among the biological indicators $\left(E_{i}\right)$, the GFP $(y)$ and time $(t)$, the starting point is to consider that it can be written as:

$$
E_{i}=E_{i}(t, y)
$$

Taking the time derivative in Eq. 10:

$$
\frac{d E_{i}(t, y)}{d t}=\frac{\partial E_{i}(t, y)}{\partial t}+\frac{\partial E_{i}(t, y) d y}{\partial y d t}
$$

Substituting Eqs. 2 and 6 in Eq. 11, taking into account Eqs, 5 and 9, and considering now that the time function $E_{i}(t)$ is, from Eq. 10, a two-variables function $E_{i}(t, y)$ :

$$
\begin{gathered}
A_{i}\left(B_{i}-E_{i}(t, y)\right)+\frac{P_{i}}{B_{i}} S(t)-B_{i} \cdot Q_{i} \cdot F_{i}(t, y)= \\
\frac{\partial E_{i}(t, y)}{\partial t}+\frac{\partial E_{i}(t, y)}{\partial y}\left(a(b-y)+\frac{p}{b} S(t)-b \cdot q \cdot z(t)\right)
\end{gathered}
$$


In Eq. $12, z(t)$ is given by Eq. 3, and $F_{i}(t, y)$, considering Eq. 7 , is given by:

$$
F_{i}(t, y)=\int_{0}^{t} \mathrm{e}^{\frac{x-t}{T_{i}}} \cdot s(x) \cdot E_{i}(x, y) d x=\mathrm{e}^{-\frac{t}{T_{i}}} \int_{0}^{t} \mathrm{e}^{\frac{x}{T_{i}}} \cdot s(x) \cdot E_{i}(x, y) d x
$$

Differing from the equation presented in [35] as the bridge model, Eq. 12 is a partial integrodifferential equation, where the integral term is due to Eq. 13, which makes difficult to handle the model mathematically. An alternative way to solve this difficulty is to consider the substitution of Eq. 10 by $E_{i}=E_{i}(t, y, z)$. This approach is held in [41], and the alternative model to Eq. 12 is provided by a set of two coupled first order partial differential equations. However, although an analytical solution seems to be impossible for both approaches, obtaining a numerical solution presents some difficulties due to the artificial dependence on $z$ in $E_{i}(t, y, z)$. The way to avoid this dependence and to avoid the direct work with a partial integro-differential equation such as Eq. 12, is to convert it into a second order partial differential equation. To do this, let us derivate Eq. 12 with respect to time:

$$
\begin{gathered}
-A_{i} \frac{\partial E_{i}(t, y)}{\partial t}+\frac{P_{i}}{B_{i}} s^{\prime}(t)-B_{i} \cdot Q_{i} \frac{\partial F_{i}(t, y)}{\partial t}=\frac{\partial^{2} E_{i}(t, y)}{\partial t^{2}}+\frac{\partial^{2} E_{i}(t, y)}{\partial t \partial y}\left(a(b-y)+\frac{p}{b} s(t)-b \cdot q \cdot z(t)\right)+\frac{\partial E_{i}(t, y)}{\partial y} \\
\left(\frac{p}{b} s^{\prime}(t)-b \cdot q \cdot z^{\prime}(t)\right)
\end{gathered}
$$

Note from Eq. 5 that $z^{\prime}(t)=-\frac{1}{\tau} z(t)+s(t) \cdot y$, and from Eq. 13:

$$
\frac{\partial F_{i}(t, y)}{\partial t}=-\frac{1}{T_{i}} \mathrm{e}^{-\frac{t}{T_{i}}} \int_{0}^{t} \mathrm{e}^{\frac{x}{T_{i}}} \cdot s(x) \cdot E_{i}(x, y) d x+\mathrm{e}^{-\frac{t}{T_{i}}} \cdot \mathrm{e}^{\frac{t}{T_{i}}} \cdot s(t) \cdot E_{i}(t, y)=-\frac{1}{T_{i}} F_{i}(t, y)+s(t) \cdot E_{i}(t, y)
$$

The substitution of Eqs. 5 and 15 in Eq. 14 provides:

$$
\begin{aligned}
&-A_{i} \frac{\partial E_{i}(t, y)}{\partial t}+\frac{P_{i}}{B_{i}} s^{\prime}(t)+\frac{B_{i} \cdot Q_{i}}{T_{i}} F_{i}(t, y)-B_{i} \cdot Q_{i} \cdot s(t) \cdot E_{i}(t, y) \\
&=\frac{\partial^{2} E_{i}(t, y)}{\partial t^{2}}+\frac{\partial^{2} E_{i}(t, y)}{\partial t \partial y}\left(a(b-y)+\frac{p}{b} s(t)-b \cdot q \cdot z(t)\right)+ \\
&+\frac{\partial E_{i}(t, y)}{\partial y}\left(\frac{p}{b} s^{\prime}(t)+\frac{b \cdot q}{\tau} \cdot z(t)-b \cdot q \cdot s(t) \cdot y\right)
\end{aligned}
$$

The next step is the elimination of the integral term $B_{i} \cdot Q_{i} \cdot F_{i}(t, y)$ in Eq. 16. First, the term is isolated from Eq. 12:

$$
\begin{aligned}
& B_{i} \cdot Q_{i} \cdot F_{i}(t, y)=A_{i}\left(B_{i}-E_{i}(t, y)\right)+\frac{P_{i}}{B_{i}} S(t)-\frac{\partial E_{i}(t, y)}{\partial t}-\frac{\partial E_{i}(t, y)}{\partial y} \\
& \left(a(b-y)++\frac{p}{b} s(t)-b \cdot q \cdot z(t)\right)
\end{aligned}
$$

Subsequently Eq. 17 is substituted in Eq. 16, and after reorganization: 


\section{The experimental designs}

The application case here considered in order to validate the response and bridge models is performed with two experimental designs on two participants that we name Case 1 and Case 2. The first design is a previous $\mathrm{AB}$ pseudo-experimental design set up for Case 1 and the second one is a subsequent $\mathrm{ABC}$ experimental design set up for Case 2. In fact, the $\mathrm{AB}$ design is not a real experimental design but an exploratory case study. Once positive results have been obtained informing about a change in the scores over the considered scales of personality when taking 20 $\mathrm{mg}$ of methylphenidate with respect to those of the base-line for Case 1, the authors decided to repeat the experiment with another subject, Case 2, but this time with a single case experimental design with three phases: A, B and C. Phase A is again the base-line, Phase B corresponds to a $20 \mathrm{mg}$ MPD intake, and Phase C to $40 \mathrm{mg}$ MPD intake.

The participants (Case 1 and Case 2) are two males 50 and 52 years old respectively. They are two voluntaries of the university teaching staff. The instruments are the Five-Adjective Scale of the General Factor of Personality (GFP-FAS) [14, 15]. The 5 adjectives are: adventurous, daring, enthusiastic, merry and bored. Each adjective is evaluated by the participants from 0 to 5 . Thus the scale for the GFP is $y \in[0,25]$.

The biological analyses to obtain the referred biological indicators are of two kinds. To obtain the c-fos and DRD3 samples, the lymphocytes of the blood samples were isolated by density centrifugation on Lymphoprep. Finally, an automated mass spectrometry platform (Sequenom, MassARRAY Quantitative Gene Expression) was used for quantification of the c-fos and the DRD3 concentrations in lymphocytes. $\beta$-actin was used as internal standard RNA. In addition, a mass spectrometer was used to obtain the glutamate level in blood. C-fos and DRD3 are measured by their molar concentration (mc) in lymphocytes in blood. The c-fos measures are 
taken on a scale multiplied by $10^{18} \mathrm{mc}$ and the DRD3 measures are taken on a scale multiplied by $10^{21} \mathrm{mc}$. With these scales, the c-fos $\left(E_{1} \equiv C\right)$ and DRD3 $\left(E_{2} \equiv D\right)$ concentrations vary in the interval $C, D \in[0,100]$. Glutamate $E_{3} \equiv G$ is measured by the direct molar concentration (mc) in blood and it is used within a scale multiplied by $10^{18} \mathrm{mc}$. With this scale, the glutamate concentration varies in the interval $G \in[0,60]$.

In all phases participants fill out the GFP-FAS form each fifteen minutes ( 17 registers each phase) and peripheral blood samples are obtained each one hour (5 samples each phase). In addition the experimental conditions take place in a hospital room a morning with an empty stomach, with no drug consumption and inside a resting and isolated atmosphere, trying to minimize the external stimuli in Phases A and also to maximize the effect of MPD in Phases B and $\mathrm{C}$.

The AB pseudo-experimental design is set up for Case 1. Phase A is the base-line, without treatment. A week later, in Phase B, Case 1 receives a dose of $20 \mathrm{mg}$ of MPD immediately after filling out the first list of the GFP-FAS form and the initial blood sample is obtained. In the following, Case 1 fills out 16 lists of the GFP-FAS, one each fifteen minutes, and a blood sample is obtained each hour along 4 hours.

One week later, the $\mathrm{ABC}$ experimental design is set up for Case 2. Phases A and B of Case 2 are set up in the same way than for Case 1, with Phases A and B separated for one week. One week later than Phase B, in Phase C, Case 2 receives a dose of $40 \mathrm{mg}$ of MPD immediately after filling out the first list of the GFP-FAS form and the initial blood sample is obtained. In the following, Case 2 fills out 16 lists of the GFP-FAS form, one each fifteen minutes, and a blood sample is obtained each hour along 4 hours.

Observe that for Case 1 in Phase B and for Case 2 in Phases B and C, each one of the measures before consuming represent the initial conditions for the response model, which is evaluated with the initial condition plus the 16 lists of the GFP-FAS. Also the response model is evaluated with the initial condition plus the 4 blood samples for the biological indicators. In addition, the bridge model can only be evaluated with those outcomes that coincide in time, i.e., with the outcomes obtained each one hour. The results of both experiments are presented in the following sections in tables and graphics, in the context of the response and bridge models validation.

\section{Validation of the response model}

The aim of this section is to validate the response model by calibration for both the GFP and the three biological indicators for both experimental designs.

The calibration method consists in comparing the experimental data obtained from the different lists of scores with the theoretical values provided by the response model. On a hand, the experimental GFP-FAS scores are compared with the theoretical outcomes provided by the $y(t)$ model variable given by Eqs. 1 and 2. On the other hand, the experimental biological scores are compared with the theoretical outcomes provided by the $E_{i}(t)$ model variables given by Eqs. 1 and 6.

To obtain the theoretical outcomes, Eqs. 2 and 6 have been programmed in $\mathrm{C}++$ language, solving the equivalent differential equations (Eqs. 4 and 5 for Eq. 2, and Eqs. 8 and 9 for Eq. 6), by the 4 th Runge-Kutta method. The $\mathrm{C}++$ program includes the algorithm to compare the 
experimental scores and the theoretical outcomes. It consists in minimizing the sum of squares of the differences between both sets of data, being the theoretical ones obtained by the corresponding equations from generating random numbers for the parameters' values. Observe that in the method development the initial value of Eq. 4, $y_{0}$, and that of Eq. 8, $E_{l}^{(0)}$, are known because they are the corresponding values obtained before the MPD stimulus is taken.

Validation only has sense when the MPD stimulus is provided, that is, for Phase B in the AB pseudo-experimental design and for Phases $\mathrm{B}$ and $\mathrm{C}$ in the $\mathrm{ABC}$ experimental design. In addition, the goodness of validation is here provided by: (a) the visual inspection of Figure 1 that represents jointly the experimental and the theoretical outcomes (GFP, c-fos, DRD3 and glutamate); (b) the determination coefficient $\left(\mathrm{R}^{2}\right)$, which varies in the interval $[0,1]$ : the closer to the unit the determination coefficient is the better the fitting degree of both data sets is.

Phases A of both experimental designs play the role of a control base-line: the observable differences between Phases A and Phases B and C (where the MPD stimulus is provided) indicate that the stimulus produces an appreciable change.

Let us start with Case 1, corresponding to the $\mathrm{AB}$ pseudo-experimental design. Phase A of Case 1 is represented in Fig. 1 (a)-(d). Note that for this case, the responses to the quietness and isolation conditions of Phase A work as a control base-line. On a hand, the experimental values change around a constant value such as it happens in Fig. 1(a) for the GFP or in Fig. 1(b) for cfos. On the other hand, Fig. 1(c) shows a slight inverted U-shape for DRD3, and Fig. 1(d) a more stressed U-shape for glutamate. However, the observed trends are different to those present in Phase B. In fact, besides, Phase B of Case 1 is represented in Figs. 1(f) - (i) as a consequence of a dose of $20 \mathrm{mg}$. Note that both the GFP (Fig. 1(f)) and c-fos (Fig. 1(g)) present a stressed inverted U-shape dynamics, while the DRD3 dynamics (Fig. 1(h)) is oscillatory and the glutamate dynamics presents a slight inverted U-shape (Fig. 1(i)). All determination coefficients range between 0.85 and 0.97 . Thus, the response model can be considered validated for Phase B of Case 1 .

In order to validate the model with Case 2, with data corresponding to the $\mathrm{ABC}$ experimental design, Phase A of Case 2 is represented in Fig. 1 (j)-(m), Phase B of Case 2 is shown in Figs. 1 (o)-(r), which illustrates the GFP, c-fos, DRD3 and glutamate dynamics as a consequence of a dose of $20 \mathrm{mg}$ of MPD. We proceed analogously to case 1 (using the same arguments). Let us remark that all determination coefficients range between 0.85 and 0.99 . Thus the response model can be considered as validated for Phase B of Case 2. Similar arguments are used for validation in Phase $\mathrm{C}$ of Case 2. Fig. 1(s)-(v) shows the determination coefficients ranges that are situated between 0.82 and 0.99 .

The corresponding optimal values of the model parameters for Phase B of Case 1 and for Phases B and C of Case 2 are presented in Table 1. Note that the parameters corresponding to the stimulus equation have the same value for the GFP and for the three biological indicators.

\section{Validation of the bridge model}


The theoretical values provided by the bridge model, $E_{i}(t, y)$, are given by the numerical solutions of Eqs.18, 19 and 20, with the optimal parameter values obtained in the calibration process of the response model (Table 1). These numerical solutions have been obtained using the NDSolve function of MATHEMATICA 10.4. On a hand, the validation of the bridge model is provided by visual inspection: the joined representation of the experimental scores and the theoretical values $E_{i}(t, y)$ of the biological indicators versus the experimental values of the GFP. On the other hand, the validation is supported by the corresponding determination coefficients of both sets of data. Note that this validation has only sense for Phase B of Case 1 and for Phases B and $\mathrm{C}$ of Case 2.

Let us consider Phase B of Case 1 and the corresponding optimal values of Table 1 to obtain the theoretical values by using the bridge model. Fig. 2 (a)-(d) presents the joined results of the experimental biological indicators and the corresponding theoretical values versus the GFP experimental values. Note that, both the visual inspection of the figures and the determination coefficients (ranging between $\mathrm{R}^{2}=0.85$ and $\mathrm{R}^{2}=0.97$ ), provide a good validation of the bridge model for Phase B of Case 1. Similar arguments can be used to validate the bridge model for the Phase $B$ of Case 2 with determination coefficients that range between $\mathrm{R}^{2}=0.85$ and $\mathrm{R}^{2}=0.99$ (see Fig. 2(e)-(g)) and, for Phase $\mathrm{C}$ of Case 2 with determination coefficients that range between $\mathrm{R}^{2}=0.82$ and $\mathrm{R}^{2}=0.99$ (see Fig. 2(h)-(k)).

The general conclusion of this section is that the bridge model can be considered as validated from the outcomes of both experimental designs.

\section{Conclusions and discussion}

The response model has been validated by calibration in the context of a previous (pilot) $\mathrm{AB}$ experiment and a subsequent $\mathrm{ABC}$ experimental design. As a consequence of getting the optimal parameter values for the response model, the presented bridge model has also been validated. Thus, it is confirmed that the GFP and the three biological indicators, c-fos, DRD3 and glutamate, vary jointly in response to a dose of a stimulating drug (MPD). In addition, the validation of the bridge model in the context of both experimental designs provides the coevolution of the GFP (mind) and the three biological indicators, c-fos, DRD3 and glutamate, (body). However, it seems obvious that future experimental designs might consider more subjects and more phases, due to the present study is centered on individuals, not in groups. The experimental designs for groups would provide statistical significations, which would increase the consistency of the response and bridge models. Besides, other kinds of stimuli should be considered in alternative experimental designs, such as caffeine, alcohol, self-regulation therapy, etc., which would also consolidate the value of the response and bridge models to study the body-mind problem.

Significant associations between the 5HTT, DRD4, DRD2, DRD3 A1/A2 polymorphisms and personality traits have been studied from different models and instruments of personality evaluation (EPQ-R, TPC, NEO, etc.) [54, 55]. In this article, we have proposed a biochemical basis (the three previously mentioned indicators) for the whole personality (General Factor of Personality) from a dynamic perspective, based on the effect of a single dose of MPD. However, in future experiments with MPD, it would be interesting to include other biochemical markers 
(such as adenosine, for instance) and further explaining the homeostatic process that occurs after taking a single dose of MPD. Now, we are going to suggest for future research a two-phase model of the effect of a single dose of MPD including some of these new markers.

MPD works in a biphasic action, including phasic and tonic release of dopamine (DA). Phasic releases of DA are large but brief and activate postsynaptic DA receptors [56, 57]. On the other hand, tonic DA release from the VTA is regulated by presynaptic NMDA receptors by glutamatergic afferents from the PFC [58].

MPD treatment produces an increase in DA signaling through multiple actions, including blockade of the DA reuptake transporter (DAT), amplification of DA response duration and activation of D1 receptors on the postsynaptic neuron [59]. Besides, MPD blockades the norepinephrine transporter (NET) resulting in elevated concentration of norepinephrine (NE) at synapses. The afferent input of glutamatergic neurons from the PFC to DA neurons in the VTA can be stimulated by MPD [60]. Low-dose MPD potentiates NMDAR functions mainly through norepinephrine system [61]. All these mechanisms correspond to the phasic action. From there the homeostatic mechanism starts.

The VTA neurons contain both D1 and D2 DA receptors. Low doses of MPD activate mainly D2-like DA auto-receptors which lead to the attenuation of DA release in response to a stimulus $[56,57]$. On the other hand, MPD increases glutamate uptake mainly expressed in glial cells. It removes the amino acid from the synaptic cleft preventing an excessive glutamatergic stimulation and thus neuronal damage [62]. This may result in a plausible regulation mechanism of the glutamatergic tone.

An important candidate to modulate dopaminergic and glutamatergic signaling and, in this way, to integrate their interactions, is adenosine. Adenosine is a neuromodulator. In the hippocampus, adenosine exerts a tonic inhibitory effect on NMDAR function via stimulation of A1Rs, thus attenuating NMDAR-mediated currents [63]. On the other hand, the adenosinedopamine receptor-receptor interacts as an integrative and homeostatic mechanism in the basal ganglia. The stimulation of adenosine receptors counteracts the behavioral effects of dopamine receptor stimulation [64].

It is known the existence of A2A-D2 and A1-D1 receptor heteromers in the brain $[64,65]$. The A1-D1 heteromeric receptor complex may be the molecular basis for the well-documented antagonistic A1-D1 receptor/receptor interactions found in the neuronal networks of the brain [64,66,67]. So, adenosine A1 receptor activation enhances of dopamine D1 receptor desensitization [68]. It has been proved the up-regulation of adenosine A1 receptor in the frontal cortex by acute administration of MPD. Since activation of adenosine A1 receptors trigger anxiolytic effects in rodents [69], this transient up-regulation of adenosine A1 receptors could be involved in the anxiolytic effects of MPD [70], as an effect of the tonic action.

In addition, mGlu5R/A2AR/D2R interactions play an important modulatory role in the function of the ventral striopallidal GABA pathway, which might have implications for the treatment of schizophrenia and drug addiction [71].

On the other hand, even though MPD does not increase the extracellular serotonin concentration in the brain [72] and its affinity to the serotonin transporter is very low [73], the serotonin can be involved in the MPD effect. So, MPD modulate the Dorsal Raphe neuronal activity as a result of an acute or repetitive dose [74], and produces selective agonist-like activity at the 5-HT1A receptor [75]. In addition, the inhibitory effect of serotonin on dopaminergic 
system has been proposed as a mechanism to produce the calming effects of MPD [76]. We can speculate that this calming effect is a result of a modulating mechanism of serotonin in the tonic action of the MPD.

Finally, Acetylcholine (Ach) appears also to be involved in the phasic-tonic response balance of dopaminergic neurons. The cholinergic input from the laterodorsal tegmental nucleus (LDT) to ventral tegmental area (VTA) is required for burst firing of dopamine cells. Activity of LDT cholinergic neurons is modulated by mAChRs (metabotropic muscarinic ACh receptors) and nAChRs (ionotropic nicotinic ACh receptors) in the LDT. The mAChRs mediating LDT-evoked striatal dopamine release may involve M3 and M5 subtypes that have been localized in the VTA. However, M3 mAChR activation appears to be involved in reducing, rather than enhancing, excitatory transmission in dopamine midbrain cells by presynaptic mechanisms [77].

These mechanisms may be playing an important role in the homeostasis produced by the MPD, since it has been verified that the MPD increases ACh efflux in cortical region, nucleus accumbens and hippocampus [78], and actives muscarinic receptors [79].

This homeostatic mechanism can be altered by the administration of high doses or by the repeated taking of MPD. The neuroadaptative mechanisms of the biological markers considered in the previous paragraphs would have to be considered in future experiments and in the corresponding mathematical models. The present research is based only on the short term dynamics described by the response model. But the response model presented in [23] provides predictions at long term. A long term stimulus-response model such as the one presented in [23] is necessary when an individual consumes many doses of a stimulant drug for a more or less long period, even of several years, with different amounts and frequencies. In fact, the model simulations of [23] predict for a period of three years, with different patterns of dose amounts and frequencies. However, the continuous consumption of different doses can elicit behavioral withdrawal, sensitization and habituation (or tolerance). These effects have been observed particularly with methylphenidate in different works [80-82]. The model presented in [23] is applied to cocaine. However, methylphenidate and cocaine share similar chemical properties and physiological effects [83-85], thus all results obtained in [23] can be translated partially to the long term effects of methylphenidate. In addition, the aforementioned biological markers would be included in these long-term models. For example, the role of adenosine receptors in psychostimulant addiction has been also proposed [86]. Therefore, a corresponding bridge model deduced under the invariance principle from the response model of [23] would be suitable to simulate changes in biology and personality at long term. This further bridge model would provide a tool to solve, for instance, problems of addiction from the double behavioral and biological perspective.

Let us stress that the bridge model is a consequence of the assumption of the mathematical invariance principle, which determines the suitability of the same mathematical structure to describe the dynamics of the GFP and that of the three biological indicators. Thus, it is here observed in action the assumption about the general applicability in behavioral sciences of the differential models used by physics and other disciplines related with applied mathematics. This assumption has been demonstrated in the last centuries in science as a method to study successfully dynamics, complexity and nonlinearity. In fact, both the response and the bridge models have been demonstrated that are two successful mathematical tools to study the coevolution of the GFP and the three biological indicators, as a consequence of a stimulus, such as 
a single dose of MPD. Then, both models provide a new perspective to study the body-mind problem.

This new perspective has to be framed in practical applications in future. In fact, a concrete application of the bridge model would consist in being used to simulate changes in biology from the self-regulation therapy: those changes that would steer biology towards suitable dynamical states for the individual personality.

Summarizing, a unified theory must consider the emergency of the physiological level from the biochemical or molecular level and, in addition, the emergency of the psychological level from the physiological level, following the three worlds of Popper's theory [41].

However, the mathematical approach here presented does not attempt to link the molecular level with the psychological level inside a reductionist "top-down" research approach. It rather attempts to state a bridge between both levels of description in the following way:

1. Both the individual dynamics of the biological molecules (molecular level) and the GFP dynamics (psychological level) can be described by the same mathematical model (the response model). Thus, in the molecular level, the response model describes the dynamics of the individual molecules involved in the mind processes, but not the complex interrelations among them.

2. The invariance principle permits to obtain the bridge model, through which the dynamics of the individual molecules can be related with the GFP dynamics in the psychological level of description.

In fact, the overall understanding of the body-mind problem must be developed in a slow step by step way that science must run in the future. For instance, one of such steps would be the study of the relationship between the physiological level of description and the psychological one, following Bunge's approach [42]. However, first of all, the own dynamics of the physiological level must be understood. Bunge presents in [42] a mathematical model of the nervous system. From the author's point of view this study can also be circumscribed to the spatio-temporal brain dynamics [87], with which the brain patterns can be studied by electrophysiological, neurobiological or fMRI data. Subsequently, the link between the GFP (psychological level) and the brain dynamics should be stated.

Finally, it is over understood by the authors that a complete solution of the body-mind problem should consider the understandings of the three levels of description: (a) at the molecular level the overall biology, which involves much more biological indicators than those here presented and their dynamical interrelationships; (b) at the physiological level, the dynamics of the nervous system activity (the general activation), and particularly the brain activity dynamics; (c) at the psychological level, the personality dynamics, both at short and at long term, including the disordered personality dynamics. And, of course, the understanding of the emergencies among the three levels must be investigated to deepen into the complexity of the body-mind problem.

\section{References}

[1] S. Amigó, La teoría del rasgo único de personalidad. Hacia una teoría unificada del cerebro y la conducta (The unique-trait personality theory. Towards a unified theory of brain and conduct), Ed. Universitat Politècnica de València, 2005.

[2] S. Amigó, A. Caselles, J.C. Micó, The General Factor of Personality Questionnaire (GFPQ): Only one factor 
to understand the personality?, Span. J. Psychol. (2010) 5-17.

[3] J.P. Rushton, T.A. Bons, J. Ando, Y.-M. Hur, P. Irwing, P.A. Vernon, K. V. Petrides, C. Barbaranelli, A General Factor of Personality From Multitrait-Multimethod Data and Cross-National Twins, Twin Res. Hum. Genet. 12 (2009) 356-365. doi:10.1375/twin.12.4.356.

[4] J.P. Rushton, T.A. Bons, Y.-M. Hur, The genetics and evolution of the general factor of personality, J. Res. Pers. 42 (2008) 1173-1185. doi:10.1016/j.jrp.2008.03.002.

[5] J.P. Rushton, P. Irwing, A General Factor of Personality (GFP) from two meta-analyses of the Big Five: and, Pers. Individ. Dif. 45 (2008) 679-683. doi:10.1016/j.paid.2008.07.015.

[6] J.P. Rushton, P. Irwing, A general factor of personality in the Comrey Personality Scales, the Minnesota Multiphasic Personality Inventory-2, and the Multicultural Personality Questionnaire, Pers. Individ. Dif. 46 (2009) 437-442. doi:10.1016/j.paid.2008.11.015.

[7] J.P. Rushton, P. Irwing, A General Factor of Personality in 16 sets of the Big Five, the Guilford-Zimmerman Temperament Survey, the California Psychological Inventory, and the Temperament and Character Inventory, Pers. Individ. Dif. 47 (2009) 558-564. doi:10.1016/j.paid.2009.05.009.

[8] J.P. Rushton, P. Irwing, A General Factor of Personality (GFP) from the Multidimensional Personality Questionnaire, Pers. Individ. Dif. 47 (2009) 571-576. doi:10.1016/j.paid.2009.05.011.

[9] J.P. Rushton, P. Irwing, A General Factor of Personality in the Millon Clinical Multiaxial Inventory-III, the Dimensional Assessment of Personality Pathology, and the Personality Assessment Inventory, J. Res. Pers. 43 (2009) 1091-1095. doi:10.1016/j.jrp.2009.06.002.

[10] L. Veselka, J.A. Schermer, K. V. Petrides, L.F. Cherkas, T.D. Spector, P.A. Vernon, A General Factor of Personality: Evidence from the HEXACO Model and a Measure of Trait Emotional Intelligence, Twin Res. Hum. Genet. 12 (2009) 420-424. doi:10.1375/twin.12.5.420.

[11] L. Veselka, J.A. Schermer, K. V. Petrides, P.A. Vernon, Evidence for a Heritable General Factor of Personality in Two Studies, Twin Res. Hum. Genet. 12 (2009) 254-260. doi:10.1375/twin.12.3.254.

[12] J.A. Schermer, P.A. Vernon, The correlation between general intelligence (g), a general factor of personality (GFP), and social desirability, Pers. Individ. Dif. 48 (2010) 187-189. doi:10.1016/j.paid.2009.10.003.

[13] S. Erdle, P. Irwing, J.P. Rushton, J. Park, The General Factor of Personality and its relation to Self-Esteem in 628,640 Internet respondents, Pers. Individ. Dif. 48 (2010) 343-346. doi:10.1016/j.paid.2009.09.004.

[14] S. Amigó, J.C. Micó, A. Caselles, Adjective scale of the unique personality trait: measure of personality as an overall and complete system, in: Proc. 7th Congr. Eur. Syst. Union, Lisboa, 2008.

[15] S. Amigó, J.C. Micó, A. Caselles, Five adjectives to explain the whole personality: a brief scale of personality, Rev. Int. Sist. (2009) 41-43. http://www.uv.es/caselles/.

[16] S. Amigó, A. Caselles, J.C. Micó, A dynamic extraversion model. The brain's response to a single dose of a stimulant drug, Br. J. Math. Stat. Psychol. 61 (2008) 211-231. doi:10.1348/000711007X185514.

[17] R.L. Solomon, J.D. Corbit, An opponent-process theory of motivation: I. Temporal dynamics of affect, Psychol. Rev. 81 (1974) 119-145. doi:10.1037/h0036128.

[18] G.F. Koob, Drug Abuse: Hedonic Homeostatic Dysregulation, Science (80-. ). 278 (1997) 52-58. doi:10.1126/science.278.5335.52.

[19] G. Koob, Drug Addiction, Dysregulation of Reward, and Allostasis, Neuropsychopharmacology. 24 (2001) 97-129. doi:10.1016/S0893-133X(00)00195-0.

[20] S. Grossberg, The imbalanced brain: from normal behavior to schizophrenia, Biol. Psychiatry. 48 (2000) 81-98. doi:10.1016/S0006-3223(00)00903-3.

[21] A. Caselles, J.C. Mico, S. Amigo, Dynamics of the General Factor of Personality in Response to a Single Dose of Caffeine, Span. J. Psychol. 14 (2011) 675-692. doi:10.5209/rev_SJOP.2011.v14.n2.16.

[22] J.C. Micó, S. Amigó, A. Caselles, Changing the General Factor of Personality and the c-fos Gene Expression with Methylphenidate and Self-Regulation Therapy, Span. J. Psychol. 15 (2012) 850-867. doi:10.5209/rev_SJOP.2012.v15.n2.38896.

[23] A. Caselles, J.C. Micó, S. Amigó, Cocaine addiction and personality: A mathematical model, Br. J. Math. Stat. Psychol. 63 (2010) 449-480. doi:10.1348/000711009X470768.

[24] M. Pompeiano, C. Cirelli, P. Arrighi, G. Tononi, c-Fos expression during wakefulness and sleep, Neurophysiol. Clin. Neurophysiol. 25 (1995) 329-341. doi:10.1016/0987-7053(96)84906-9.

[25] S.J. Meador-Wooddruff, J. H., Mansour, A., Saul, J., \& Watson, Neuroanalomical distribution of 
dopamine receptor messenger RNAs, in: H.B. Niznik (Ed.), Dopamine Recept. Transp., Marcel Dekker, New York, 1994: pp. 401-415.

[26] B. Levant, The D 3 Dopamine Receptor : Neurobiology and Potential Clinical Relevance, Pharmacol. Rev. 49 (1997) 231-252.

[27] C. Czermak, M. Lehofer, H. Renger, E.M. Wagner, L. Lemonis, A. Rohrhofer, K. Schauenstein, P.M. Liebmann, Dopamine receptor D3 mRNA expression in human lymphocytes is negatively correlated with the personality trait of persistence, J. Neuroimmunol. 150 (2004) 145-149. doi:10.1016/j.jneuroim.2004.01.009.

[28] S. Caine, G. Koob, Modulation of cocaine self-administration in the rat through D-3 dopamine receptors, Science (80-. ). 260 (1993) 1814-1816. doi:10.1126/science.8099761.

[29] B.J. Everitt, P. Sokoloff, M. Pilla, S. Perachon, F. Sautel, F. Garrido, A. Mann, C.G. Wermuth, J.-C. Schwartz, Selective inhibition of cocaine-seeking behavior by a partial dopamine D3 receptor agonist, Nature. 400 (1999) 371-375. doi:10.1038/22560.

[30] S. Amigó, A. Caselles, J.C. Micó, Self-Regulation Therapy to Reproduce Drug Effects: A Suggestion Technique to Change Personality and the DRD3 Gene Expression, Int. J. Clin. Exp. Hypn. 61 (2013) 282304. doi:10.1080/00207144.2013.784094.

[31] J.. Amigó, S., Caselles, A., Micó, J.C., García, Dynamics of the unique trait of personality: blood's glutamate in response to methylphenidate and conditioning, Rev. Int. Sist. 16 (2009) 35-40.

[32] N.D. Volkow, L. Chang, G.-J. Wang, J.S. Fowler, Y.-S. Ding, M. Sedler, J. Logan, D. Franceschi, J. Gatley, R. Hitzemann, A. Gifford, C. Wong, N. Pappas, Low Level of Brain Dopamine D 2 Receptors in Methamphetamine Abusers: Association With Metabolism in the Orbitofrontal Cortex, Am. J. Psychiatry. 158 (2001) 2015-2021. doi:10.1176/appi.ajp.158.12.2015.

[33] N. Volkow, Role of dopamine in the therapeutic and reinforcing effects of methylphenidate in humans: results from imaging studies, Eur. Neuropsychopharmacol. 12 (2002) 557-566. http://linkinghub.elsevier.com/retrieve/pii/S0924977X02001049.

[34] J.C. Micó, A. Caselles, S. Amigó, A. Cotolí, M.T. Sanz, A Mathematical Approach to the Body-Mind Problem from a System Personality Theory (A Systems Approach to the Body-Mind Problem), Syst. Res. Behav. Sci. 30 (2013) 735-749. doi:10.1002/sres.2241.

[35] J.C. Micó, S. Amigó, A. Caselles, From the Big Five to the General Factor of Personality: a Dynamic Approach, Span. J. Psychol. 17 (2014) E74. doi:10.1017/sjp.2014.71.

[36] P.F. Martínez-Freire, Del problema mente-cuerpo al problema mente-cerebro. (From the body-mind problem to the brain-mind problem), in: A. Segura (Ed.), Hist. Univers. Del Pensam. Filosófico, Liber Ortuella, Vizcaya, 2007: p. vol.5, 799-811.

[37] J. Murphy, Wittgenstein on the Mind-Body Relationship, 2006. http://hdl.handle.net/11375/10673.

[38] A. Pascual-Leone, F. Tarazona, J. Keenan, J.M. Tormos, R. Hamilton, M.D. Catala, Transcranial magnetic stimulation and neuroplasticity, Neuropsychologia. 37 (1998) 207-217. doi:10.1016/S0028-3932(98)000955.

[39] R. Ader, R. Ader, N. Cohen, N. Cohen, Behaviorally conditioned immunosuppression., Psychosom. Med. 37 (1975) 333-40. doi:10.1126/science.7063864.

[40] R. Ader, Behavioral influences on immune responses, in: S.M. Weiss, J.A. Hard, B.H. Fox (Eds.), Perspect. Behav. Med., Academic Press, New York, 1981.

[41] K.R. Popper, Knowledge and the Body-Mind Problem. In defence of interaction, Routlge, New York, 1994.

[42] M. Bunge, The body-mind problem. A psychobiological approach, Pergamon Press, Oxford, 2002.

[43] Motterlini. M., The Myth of the Framework: In Defence of Science and Rationality. Karl R. Popper, M. A. Notturno Knowledge and the Body-Mind Problem: In Defence of Interaction. Karl R. Popper, M. A. Notturno, Isis. 90 (1999) 639-641.

[44] G.-L. Lueken, Karl R. Popper, The Myth of the Framework and Knowledge and the Body-Mind Problem, Philos. Investig. (1997) 69-75.

[45] M. Ben-Chaim, Knowledge and the Body-Mind Problem \&amp; The Myth of the Framework by Karl Popper, Philosophia (Mendoza). 26 (1998) 529-544. doi:10.1007/BF02381509.

[46] I. Gold, D. Stoljar, A neuron doctrine in the philosophy of neuroscience, Behav. Brain Sci. 22 (1999). doi:10.1017/S0140525X99002198. 
[47] J.M. Zanker, Playing with words, working with concepts, testing ideas, Behav. Brain Sci. 22 (1999) S0140525X99512193. doi:10.1017/S0140525X99512193.

[48] J. Agassi, The changing features of the body-mind problem, J. Physiol. 101 (2007) 153-160. doi:10.1016/j.jphysparis.2007.11.010.

[49] H. Haken, Brain dynamics. Synchronization and activity patterns in pulse-coupled neural nets with delays and noise, Springer, New York, 2002.

[50] M. Brearley, Psychoanalysis and the Body-Mind Problem, Ratio. 15 (2002) 429-443. doi:10.1111/14679329.00201.

[51] F. Scalzone, Notes for a dialogue between psychoanalysis and neuroscience 1, Int. J. Psychoanal. 86 (2005) 1405-1423. doi:10.1516/9KGQ-67A1-RA5H-96L6.

[52] E. Basar, B. Guntekin, A breakthrough in neuroscience needs a "Nebulous Cartesian System". Oscillations, quantum dynamics and chaos in the brain and vegetative system, Int. J. Psychophysiol. 64 (2007) 108-122. doi:10.1016/j.ijpsycho.2006.07.012.

[53] A.P. Dvoryanchikova, I.M. Delamer, J.L.Martínez, An Approach to Cognition in Factory Automation by applying Functional Systems Theory, in: 2007 5th IEEE Int. Conf. Ind. Informatics, IEEE, 2007: pp. 621625. doi:10.1109/INDIN.2007.4384845.

[54] M.R. Munafò, T.G. Clark, L.R. Moore, E. Payne, R. Walton, J. Flint, Genetic polymorphisms and personality: A systematic review and metaanalysis. Molecular Psychiatry 8 (2003) 471-84. doi: $10.1038 /$ sj.mp.4001326.

[55] S. Sanchez-Roige, J.C. Gray, J. MacKillop, C.H. Chen, A.A. Palmer, The genetics of human personality. Genes Brain Behav. (2018) 17(3) e12439. doi:10.1111/gbb.12439

[56] P. Seeman, B.K. Madras, Anti-hyperactivity medication: methylphenidate and amphetamine, Mol. Psychiatry. 3 (1998) 386-396. https://doi.org/10.1038/sj.mp.4000421

[57] P. Seeman, B. Madras, Methylphenidate elevates resting dopamine which lowers the impulse-triggered release of dopamine: a hypothesis, Behav. Brain Res. 130 (2002) 79-83. doi: 10.1016/s01664328(01)00435-1.

[58] A.A. Grace, Phasic versus tonic dopamine release and the modulation of dopamine system responsivity: a hypothesis for the etiology of schizophrenia, Neuroscience. 41 (1991) 1-24. doi: 10.1016/03064522(91)90196-u.

[59] T.E. Wilens, Effects of methylphenidate on the catecholaminergic system in attention-deficit/hyperactivity disorder, J Clin Psychopharmacol 28 (2008) 46-53. doi: 10.1097/JCP.0b013e318173312f.

[60] Z. Jones, N. Dafny, Acute and chronic dose-response effect of methylphenidate on ventral tegmental area neurons correlated with animal behavior, J Neural Transm 121 (2014) 327-345. DOI: 10.1007/s00702-0131101-2.

[61] J. Hannestad, J.D. Gallezot, B. Planeta-Wilson, S.F. Lin, W.A. Williams, C.H. van Dyck et al., Clinically relevant doses of methylphenidate significantly occupy norepinephrine transporters in humans in vivo. Biol Psychiatry. 68 (2010) 854-60. doi: 10.1016/j.biopsych.2010.06.017.

[62] A.M. Guillem, Z. Martinez-Lozada, L.C. Hernandez-Kelly, E. Lopez-Bayghen, B. Lopez-Bayghen, O.A. Calleros, et al., Methylphenidate increases glutamate uptake in bergmann glial cells. Neurochem. Res. 40 (2015) 2317-2324. doi: 10.1007/s11064-015-1721-z.

[63] D. Boison, P. Singer, H.Y. Shen, J. Feldon, B.K. Yee, Adenosine hypothesis of schizophreniaopportunities for pharmacotherapy. Neuropharmacology 62 (2012) 1527-1543. doi: 10.1016/j.neuropharm.2011.01.048.

[64] S. Ferré, B.B. Fredholm, M. Morelli, P. Popoli, K. Fuxe, Adenosine-dopamine receptor-receptor interactions as an integrative mechanism in the basal ganglia. Trends Neurosci. 20 (1997) 482-487. doi: 10.1016/s0166-2236(97)01096-5.

[65] R. Franco, V. Casado, A. Cortes, C. Ferrada, J. Mallol, A. Woods C. Lluis, E.I. Canela, S. Ferré, Basic concepts in Gprotein-coupled receptor homo- and heteromerization. Sci.World J. 7 (2007) 48-57. DOI $10.1100 /$ tsw.2007.197

[66] K. Fuxe, S. Ferré, M. Zoli, L.F. Agnati, Integrated events in central dopamine transmission as analyzed at multiple levels. Evidence for intramembrane adenosine A2A/dopamine D2 and adenosine A1/dopamine D1 receptor interactions in the basal ganglia. Brain Res. Rev. 26 (1998) 258-273. doi: 10.1016/s01650173(97)00049-0.

[67] R. Franco, S. Ferré, L. Agnati, M. Torvinen, S. Ginés, J. Hillion, V. Casadó, P. Lledó, M. Zoli, C. Lluis, K. Fuxe, Evidence for adenosine/dopamine receptor interactions: indications for heteromerization. 
Neuropsychopharmacology 23 (4 Suppl) (2000) S50-S59. doi: 10.1016/S0893-133X(00)00144-5.

[68] Y. Cao, K.Q. Xie, X.Z. Zhu, (2007) The enhancement of dopamine D1 receptor desensitization by adenosine A1 receptor activation, Eur. J. Pharmacol. 562 (2007) 34-38. doi: 10.1016/j.ejphar.2007.01.090.

[69] N. Jain, N. Kemp, O. Adeyemo, P. Buchanan, T.W. Stone, Anxiolytic activity of adenosine receptor activation in mice. Br.J. Pharmacol. 116 (1995) 2127-2133. doi: 10.1111/j.1476-5381.1995.tb16421.x

[70] S. Mioranzza, P.H. Botton, M.S. Costa, J. Espinosa, V. Kazlauckas, A.P. Ardais, D.O. Souza, L.O. Porciúncula, Adenosine A1 receptors are modified by acute treatment with methylphenidate in adult mice. Brain Res. 1357 (2010) 62-69. doi: 10.1016/j.brainres.2010.08.004.

[71] Z. Díaz-Cabiale, M. Vivo, A. Del Arco, W.T. O’Connor, M.K. Harte, C.E. Müller, E. Martínez, K. Fuxe, P. Popoli, S. Ferré, Metabotropic glutamate mGlu5 receptormediated modulation of the ventral striopallidal GABA pathway. Interactions with adenosine A2A and dopamine D2 receptors. Neurosci Lett. 324 (2002) 154-158. doi: 10.1016/s0304-3940(02)00179-9.

[72] R. Kuczenski, D.S. Segal, Effects of methylphenidate on extracellular dopamine, serotonin, and norepinephrine: comparison with amphetamine. J Neurochem. 68 (1997) 2032-2037. doi: 10.1046/j.14714159.1997.68052032.x.

[73] S.J. Gatley, D. Pan, R. Chen, G. Chaturvedi, Y.S. Ding, Affinities of methylphenidate derivatives for dopamine, norepinephrine and serotonin transporters. Life Sci. 58 (1996) 231-239. doi: 10.1016/00243205(96)00052-5.

[74] B. Tang, N. Dafny, Dorsal raphe neuronal activities are modulated by methylphenidate. J Neural Transm. 120 (2013) 721-731. doi: 10.1007/s00702-012-0917-5.

[75] J. Markowitz, C. Devane, S. Ramamoorthy, H-J. Zhu, The psychostimulant d-threo-(R, R)Methylphenidate binds as an agonist to the 5HT1A receptor. Die Pharmazie 64(2) (2009) 123-125.

[76] R.R. Gainetdinov, W.C. Wetsel, S.R. Jones, E.D. Levin, M. Jaber, M.G. Caron, Role of serotonin in the paradoxical calming effect of psychostimulants on hyperactivity. Science 283 (1999) 397- 402. doi: 10.1126/science.283.5400.397.

[77] D.B. Lester, T.D. Rogers, C.D. Blaha, Acetylcholine-dopamine interactions in the pathophysiology and treatment of CNS disorders. CNS Neurosci. Ther. 16 (2010) 137-162. doi: 10.1111/j.17555949.2010.00142.x.

[78] E.T. Tzavara, F.P. Bymaster, C.D. Overshiner, R.J. Davis, K.W. Perry, M. Wolff et al. Procholinergic and memory enhancing properties of the selective norepinephrine uptake inhibitor atomoxetine. Mol Psychiatry 11 (2006) 187-195. doi: 10.1038/sj.mp.4001763.

[79] T.J. Volz, S.J. Farnsworth, S.D. Rowley, G.R. Hanson. A.E. Fleckenstein, Methylphenidate-induced increases in vesicular dopamine sequestration and dopamine release in the striatum: the role of muscarinic and dopamine D2 receptors. J. Pharmacol. Exp. Ther. 327 (2008) 161-167. doi: 10.1124/jpet.108.139386.

[80] N. Dafny, P. B. Yang, The role of age, genotype, sex, and route of acute and chronic administration of methylphenidate: a review of its locomotor effects, Brain Res Bull 68 (2006) 393-405. doi: 10.1016/j.brainresbull.2005.10.005.

[81] J, Godfrey, Safety of therapeutic methylphenidate in adults: a systematic review of the evidence, J Psychopharmacol 23 (2009) 194-205. doi: 10.1177/0269881108089809.

[82] P. B. Yang, A. C. Swann, N. Dafny, Chronic administration of methylphenidate produces neurophysiological and behavioral sensitization. Brain Res 1145 (2007) 66-80. doi: 10.1016/j.brainres.2007.01.108.

[83] G-J. Wang, N. D. Volkow, R. J. Hitzemann, C. Wong, B. Angrist, G. Burr, K. Pascani, N. Pappas, A, Lu, T. Cooper, J. A. Lieberman, Behavioral and cardiovascular effects of intravenous methylphenidate in normal subjects and cocaine abusers Eur Addiction Res 3 (1997) 49-54.

[84] N. D. Volkow, J. S. Fowler, S. J. Gatley, S. L. Dewey, G. J. Wang, J. Logan, Y. S. Ding, D. Franceschi, A. Gifford, A. Morgan, N. Pappas, P. King, Comparable changes in synaptic dopamine induced by methylphenidate and by cocaine in the baboon brain, Synapse 31 (1999) 59 -66. doi: 10.1002/(SICI)10982396(199901)31:1<59::AID-SYN8>3.0.CO;2-Y.

[85] N. D. Volkow, Y-S. Ding, J. S. Fowler, G. J. Wang, J. Logan, J. S. Gatley, S. L. Dewey, C. Ashby, J. Lieberman, R. Hitzemann, A. P. Wolf, Is methylphenidate like cocaine? Studies on their pharmacokinetics and distribution in human brain, Arch Gen Psychiatry 52 (1995) 456-463. doi: 10.1001/archpsyc.1995.03950180042006.

[86] I. Ballesteros-Yáñez, C.A. Castillo, S. Merighi, S. Gessi, The Role of Adenosine Receptors in Psychostimulant Addiction. Front. Pharmacol 8 (2018) 985. 8. https://doi.org/10.3389/fphar.2017.00985. 
[87] J.C. Micó, A. Caselles, S. Amigó, D. Soler, Maria T. Sanz, The quantum brain model, in: Modelling for Engineering \& Human Behaviour, Valencia, 2019. 


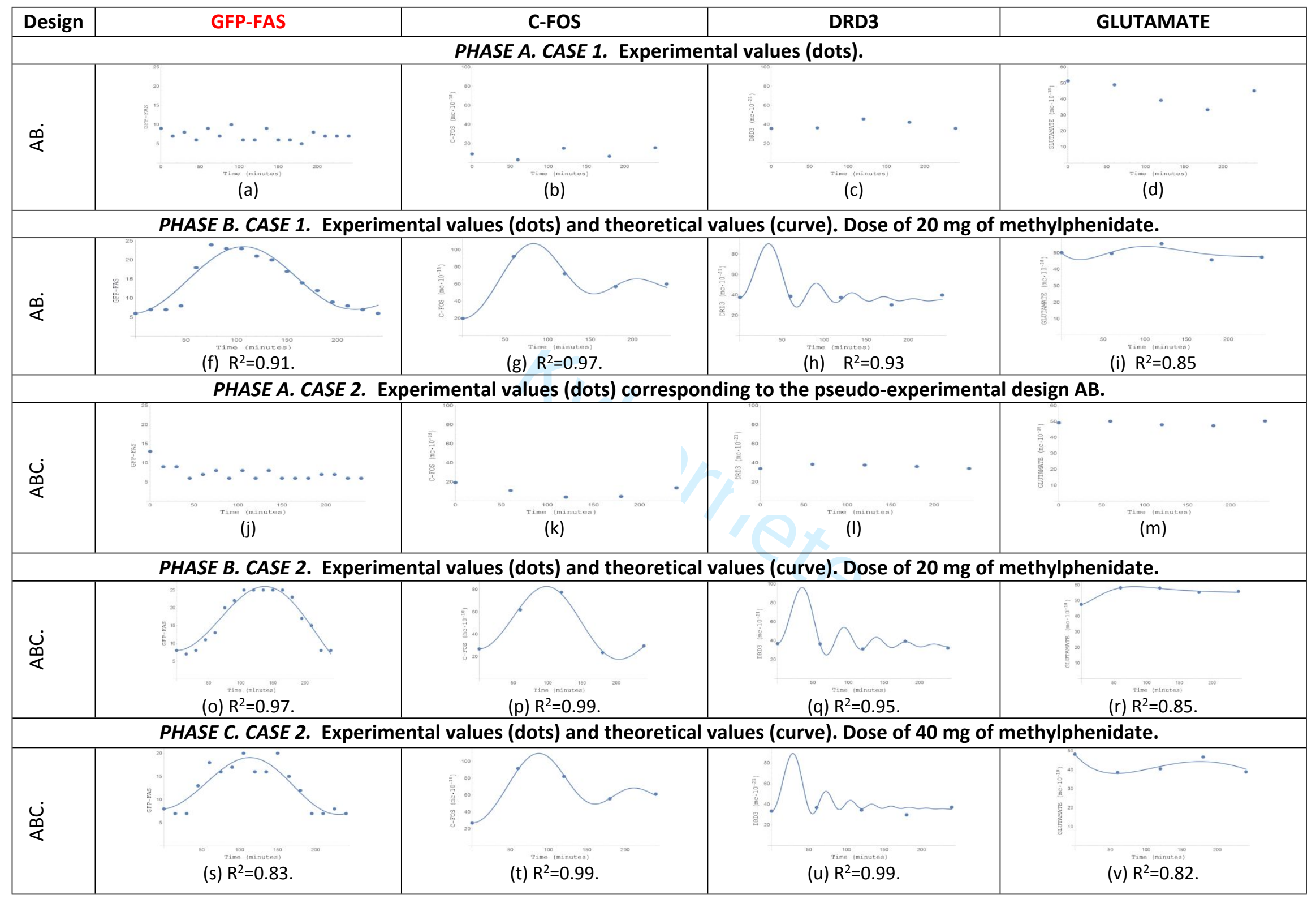

Figure 1 Validation of the response and bridge models. 


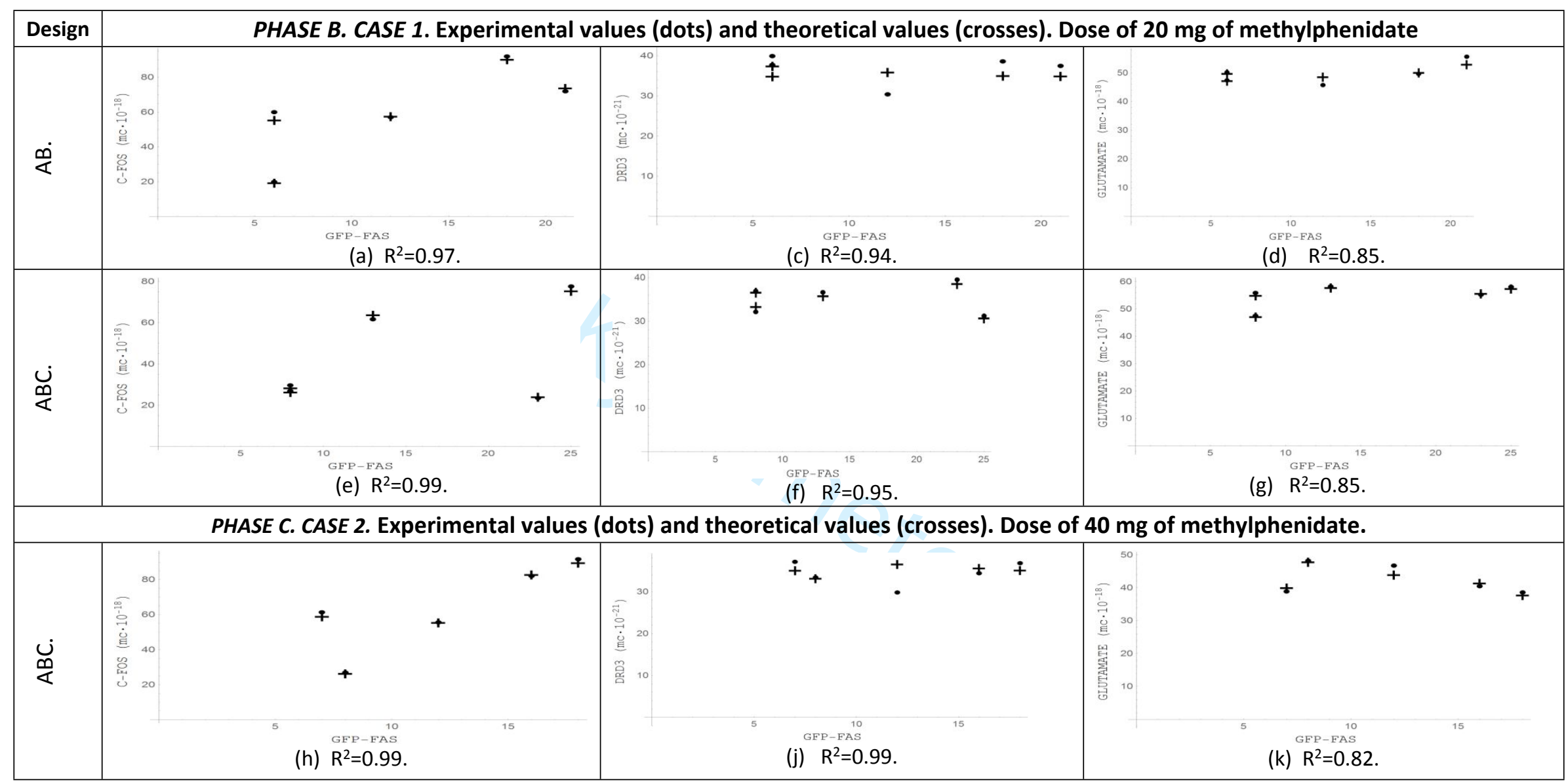

Figure 2. Comparison between theoretical and experimental values of GFP-FAS in the different cases and doses 
AB Design . PHASE B. CASE 1. Dose of $20 \mathrm{mg}$ of methylphenidate.

\begin{tabular}{|c|c|c|c|c|}
\hline Parameters & GFP dynamics & C-FOS & DRD3 & GLUTAMATE \\
\hline Methylphenidate dose (M) & $2.0000 \mathrm{e}+001$ & $2.0000 \mathrm{e}+001$ & $2.0000 \mathrm{e}+001$ & $2.0000 \mathrm{e}+001$ \\
\hline Inhibitor effect delay $\left(T_{i}\right)$ & $1.0213 e+002$ & $4.3812 e+001$ & $3.0735 e+001$ & $3.6923 e+001$ \\
\hline Assimilation rate $(\alpha)$ & $3.2861 \mathrm{e}-003$ & $3.2861 \mathrm{e}-003$ & $3.2861 \mathrm{e}-003$ & $3.2861 \mathrm{e}-003$ \\
\hline Distribution rate $(\beta)$ & $8.8380 \mathrm{e}-004$ & $8.8380 \mathrm{e}-004$ & $8.8380 \mathrm{e}-004$ & 8.8380e-004 \\
\hline Homeostatic control power $\left(A_{i}\right)$ & $4.9064 \mathrm{e}-003$ & $6.3018 \mathrm{e}-004$ & $4.0129 \mathrm{e}-003$ & $1.7164 \mathrm{e}-002$ \\
\hline Tonic level $\left(B_{i}\right)$ & $1.0924 \mathrm{e}+001$ & $1.4871 \mathrm{e}+001$ & $1.6519 \mathrm{e}+001$ & $2.3570 \mathrm{e}+001$ \\
\hline Excitation effect power $\left(\mathrm{P}_{\mathrm{i}}\right)$ & $1.3322 \mathrm{e}+000$ & $1.4456 \mathrm{e}+001$ & $6.3232 \mathrm{e}+001$ & $8.5710 \mathrm{e}+000$ \\
\hline Inhibitor effect power $\left(\mathrm{Q}_{\mathrm{i}}\right)$ & $1.2676 \mathrm{e}-005$ & $2.8545 \mathrm{e}-005$ & $2.3233 e-004$ & $8.4998 \mathrm{e}-006$ \\
\hline \multicolumn{5}{|c|}{ ABC Design. PHASE B. CASE 2. Dose of $20 \mathrm{mg}$ of methylphenidate. } \\
\hline & GFP dynamics & C-FOS & DRD3 & GLUTAMATE \\
\hline Methylphenidate dose (M) & $2.0000 \mathrm{e}+001$ & $2.0000 \mathrm{e}+001$ & $2.0000 e+001$ & $2.0000 \mathrm{e}+001$ \\
\hline Inhibitor effect delay (Ti) & $1.7473 e+002$ & $8.2863 e+001$ & $3.1139 \mathrm{e}+001$ & $1.1166 \mathrm{e}+001$ \\
\hline Assimilation rate $(\alpha)$ & $5.3711 \mathrm{e}-003$ & 5.3711e-003 & 5.3711e-003 & $5.3711 \mathrm{e}-003$ \\
\hline Distribution rate $(\beta)$ & $1.5732 \mathrm{e}-003$ & $1.5732 \mathrm{e}-003$ & $1.5732 \mathrm{e}-003$ & $1.5732 \mathrm{e}-003$ \\
\hline Homeostatic control power (Ai) & 2.6764e-004 & 0 & $2.8734 \mathrm{e}-004$ & $1.2631 \mathrm{e}-002$ \\
\hline Tonic level (Bi) & $4.6680 \mathrm{e}+000$ & $2.0365 e+001$ & $1.8213 e+001$ & $5.3462 \mathrm{e}+001$ \\
\hline Excitation effect power $\left(P_{i}\right)$ & 2.4243e-001 & $6.1950 e+000$ & $4.4131 \mathrm{e}+001$ & $1.1024 \mathrm{e}+001$ \\
\hline Inhibitor effect power (Qi) & $8.4485 e-006$ & $5.7396 \mathrm{e}-006$ & $1.2699 \mathrm{e}-004$ & $6.2781 \mathrm{e}-006$ \\
\hline \multicolumn{5}{|c|}{ ABC Design . PHASE C. CASE 2. Dose of $\mathbf{4 0 ~} \mathbf{~ m g}$ of methylphenidate. } \\
\hline & GFP dynamics & C-FOS & DRD3 & GLUTAMATE \\
\hline Methylphenidate dose (M) & $4.0000 \mathrm{e}+001$ & $4.0000 \mathrm{e}+001$ & $4.0000 e+001$ & $4.0000 \mathrm{e}+001$ \\
\hline Inhibitor effect delay (Ti) & $9.1556 e+001$ & $4.7736 e+001$ & $2.4158 e+001$ & $9.8056 e+002$ \\
\hline Assimilation rate $(\alpha)$ & $1.0778 \mathrm{e}-003$ & $1.0778 \mathrm{e}-003$ & $1.0778 \mathrm{e}-003$ & $1.0778 \mathrm{e}-003$ \\
\hline Distribution rate $(\beta)$ & 7.4257e-004 & 7.4257e-004 & 7.4257e-004 & 7.4257e-004 \\
\hline Homeostatic control power (Ai) & $1.7457 \mathrm{e}-003$ & 0 & $5.3887 \mathrm{e}-003$ & $1.4485 \mathrm{e}-002$ \\
\hline Tonic level (Bi) & $1.6158 \mathrm{e}+001$ & $2.5438 \mathrm{e}+001$ & $8.4389 e+000$ & $1.8165 \mathrm{e}+001$ \\
\hline Excitation effect power $\left(P_{i}\right)$ & $1.6580 \mathrm{e}+000$ & $3.1705 e+001$ & $7.2391 \mathrm{e}+001$ & $2.7192 \mathrm{e}+000$ \\
\hline Inhibitor effect power (Qi) & $9.4120 \mathrm{e}-006$ & $2.0085 \mathrm{e}-005$ & $1.2778 \mathrm{e}-003$ & $1.3752 \mathrm{e}-006$ \\
\hline
\end{tabular}

Table 1. Optimal values of the response model for different cases. 


\title{
Biology and personality: a mathematical approach to the body-mind problem
}

\begin{abstract}
Purpose - The purpose of this paper is to investigate the body-mind problem from a mathematical invariance principle that relates personality dynamics in two levels of description: the psychological and the biological levels.

Design/methodology/approach - The relationship between the two levels of description is provided by two mathematical models: the response model and the bridge model. The response model, an integro-differential equation, is capable to reproduce the personality dynamics as a consequence of a determined stimulus. The invariance principle asserts that the response model can reproduce the personality dynamics at the two levels of description. As a consequence, the bridge model, a second order partial differential equation, can be deduced: it provides the coevolution of the GFP (mind) and the c-fos, DRD3 and glutamate (body).
\end{abstract}

Findings - An application case is presented by setting up two experimental designs: a previous pilot AB pseudoexperimental design with a subject and a subsequent $\mathrm{ABC}$ experimental design with another subject, where the stimulus used is the stimulant drug methylphenidate. With the outcomes of the application case the response and the bridge models are validated.

Originality/value - The mathematical approach presented is based on a holistic personality model developed in the last years: the Unique Trait Personality Theory, which claims for a single trait, the General Factor of Personality, to understand the overall human personality.

Keywords: body-mind problem; general factor of personality; response model; integro-differential equation; bridge model; second order partial differential equation; c-fos; DRD3; glutamate; methylphenidate.

\section{Introduction}

The objective of this paper is to provide a mathematical approach to the body-mind problem

based on a holistic personality model developed in the last years: the Unique Trait Personality Theory (UTPT) [1, 2]. The UTPT claims for a unique trait, as synonymous of single trait, to understand the overall human personality. The concept "unique trait" is substituted latter by the equivalent concept of General Factor of Personality (GFP) in the work [2], in order to follow the generally accepted scientific term.

The studies about the central concept of GFP proposed by the UTPT define a new, emergent and novel field inside personality research. It treats about "the single general factor hypothesis" and proposes a general factor of personality within the Big Five Factors (B5F) model (the five factors are: Extraversion, Responsibility, Neuroticism, Openness to Experience and Agreeableness), occupying the GFP the apex of the hierarchy of personality factors $[3,4,5,6,7$, 8, 9, 10, 11, 12, 13]. The Five-Adjective Scale of the General Factor of Personality (GFP-FAS) $[14,15]$ offers the possibility to measure the dynamical change of the GFP in a single individual, due to its strong correlation with the GFP questionnaire [2]. Thus, having a dynamically observable instrument to measure the GFP (the GFP-FAS) is fundamental for the here presented dynamical mathematical approach to the body-mind problem. 
In addition, the GFP has a physiological base, given by the general activation of the stress system (general activation, for short). The general activation is also particularly asserted as the brain activation level if it is particularized to the general activation in brain [2, 16]. Moreover, two kinds of general activation can be distinguished depending on the conditions acting on the stress system: the tonic general activation (the state of the general activation in absence of stimuli), and the phasic general activation (the dynamic response of the general activation as a consequence of one or more stimuli). Both the psychological level of description, given by the GFP, and its corresponding physiological level of description, given by the general activation, can change along time as a consequence of a stimulus.

The biological level of description has to be taken into account for an overall personality description. The biological level is constituted by the biochemical indicators related to personality and their dynamical interrelationships. The three biochemical indicators considered in this paper are the regulator gens c-fos and DRD3, and the neurotransmitter glutamate. They have been chosen due to their close relationship with personality, such as it is tried to be demonstrated in the following paragraphs.

The scientific literature shows a close relationship between personality and c-fos expression. Take into account that c-fos expression is considerably increased in brain's regions involved in the regulation of arousal states, such as the locus coeruleus (noradrenergic neurons) and the medial preoptic area (non-GABAergic neurons) [24]. In [22] it is demonstrated that the response model is capable to reproduce the joint dynamics of the immediate-early gen c-fos (body) and the GFP (mind) as a consequence of a methylphenidate dose and suggests the need to deepen into this relationship from a mathematical approach.

There is also a close relationship between personality and DRD3 expression. For instance, DRD3 is considered to play a major role in cognition and emotion [25], in neuropsychiatric diseases [26], and in personality [27]. Further, there is evidence that DRD3 plays a role in addiction mechanisms, such as drug-seeking and drug-taking behavior [28, 29]. In fact, the work [30] demonstrates that, such as it happens in the experimental designs of [2], a self-regulation therapy produces changes in the GFP (mind) and the DRD3 expression (body), which brings us again the need to deepen into this relationship from a mathematical approach.

Besides, glutamate is not only a neurotransmitter. Glutamate has regulatory functions in immune-component cells and in nervous system. Glutamate is an indicator of the organism's general state of activation, and thus of the GFP. In fact, the joint dynamics of glutamate and the GFP has been successfully described with the response model as a consequence of a methylphenidate dose in [31]. This work [31] demonstrates again the need to deepen into this relationship from a mathematical approach.

The use of methylphenidate as the stimulus in the application case presented here is suitable. Actually, such as the works $[32,33]$ demonstrate, a previous dopamine deficit in brain favors a greater increase of dopamine in brain in response to a dose of methylphenidate [1]. Note that the 
increase of dopamine in the brain is equivalent to an increase of the general activation, and thus of the GFP.

The here presented response model is an integro-differential equation that is a generalization of the model presented in [16]. It has been validated in [21] when the stimulus is caffeine and in [22] when the stimulus is methylphenidate. The model reproduces accurately the dynamic patterns of the brain activation as a consequence of a stimulant drug intake, such as it is predicted by the works $[17,18,19,20]$. These works predict a general dynamic pattern given by an inverted U-shape, but other exceptional patterns can also be observed, such as an inverted-U followed by a recovering $U$, a decaying $U$ from the beginning until the end of the experimental period or a growth that tends to maintain a constant value in the experimental period. In addition, the generalized response model is the here used one to reproduce the dynamics of the GFP, the c-fos, the DRD3 and the glutamate, as a consequence of a methylphenidate dose intake.

An important assumption to relate mathematically the psychological level of description (mind) with the biological level of description (body) is the invariance principle. It asserts that the response model has the same mathematical structure to describe both the dynamics of the GFP (mind) and the biochemical indicators related to personality (body): c-fos, DRD3 and glutamate. As a consequence of the invariance principle, the so-called bridge model, a second order partial differential equation, can be deduced. The bridge model provides the co-evolution or dynamical relationship between every biochemical indicator, the GFP and time (through the time dependence of the stimulus).

Two previous versions of the bridge model have also been used in personality theory [34, 35]. However, the here deduced bridge model version presents a theoretical advance, respect to the models presented in $[34,35]$. On a hand, the bridge model proposed in [35] relates the Big Five Factors (B5F) with the GFP and time. It has the restriction that no inhibitor delay (see Section 2, for the meaning of this term) is present in the simplified version of the response model that the authors applied to both the GFP and the B5F dynamics. Its validation takes place in the context of an experimental design where the participants consumed caffeine. In that case, the deduced bridge model is a first order partial differential equation that relates every component of the B5F with the GFP and time. On the other hand, the referred inhibitor delay is considered in [12] to develop a first mathematical approach about the body-mind problem by using another bridge model: a set of two coupled first order partial differential equations that relates c-fos and glutamate with the GFP response and time. Its validation takes place in the context of an experimental design where the participants consumed methylphenidate. However, despite its generality, obtained by including the inhibitor delay term, that model produces in some cases artificial singularities due to the imprecision to state boundary conditions, which makes difficult to handle it numerically. The bridge model proposed in the present paper reformulates the two coupled partial differential equations as a second order partial differential equation, on which two boundary conditions are precisely formulated and no singularities are observed, which makes easier to handle it numerically.

This paper is organised as follows. Section 2 the response model is presented and explained. Section 3 the bridge model is deduced from the response model by the invariance principle. Section 4 is devoted to present the experimental designs. The results obtained from them are used to 
validate the response model for the GFP and the biological indicators (c-fos, DRD3, and glutamate) in Section 5, and to validate the bridge model in Section 6. The conclusions of the work are presented in Section 7, together with the paper discussion.

\section{The response model}

The response model is the mathematical tool used to compute the short term dynamics of the GFP as a result of a stimulus produced by a single dose intake of a drug, such as it has been used in $[16,21,22,31,34,35]$. Let us recall the response model in the following paragraphs.

Assuming that no drug is present in the organism before consuming it, the stimulus time dependence $s(t)$, i.e., the amount of drug in the organism not yet consumed (or metabolized) by cells at time $t$, is provided by the function:

$$
s(t)=\left\{\begin{array}{c}
\frac{\alpha \cdot M}{\beta-\alpha}(\exp (-\alpha \cdot t)-\exp (-\beta \cdot t)): \alpha \neq \beta \\
\alpha \cdot M \cdot t \cdot \exp (-\alpha \cdot t): \alpha=\beta
\end{array}\right.
$$

In Eq. $1, M$ is the initial amount of a drug single dose, $\alpha$ is the drug assimilation rate, and $\beta$ is the stimulus elimination rate.

The dynamics of the GFP is given by the following equation:

$$
\left.\begin{array}{c}
\frac{d y(t)}{d t}=a(b-y(t))+\frac{p}{b} s(t)-b \cdot q \cdot \int_{0}^{t} \mathrm{e}^{\frac{x-t}{\tau}} \cdot s(x) \cdot y(x) d x \\
y(0)=y_{0}
\end{array}\right\}
$$

Eqs. 1 and 2 represent the response model. In Eq. 2, $s(t)$ represents the stimulus given by Eq. 1; $y(t)$ represents the GFP dynamics; and $b$ and $y_{0}$ are respectively its tonic level and its initial value. The dynamics of Eq. 2 is a balance of three terms, which provide the time derivative of the GFP: the homeostatic control $(a(b-y(t)))$, i.e., the cause of the fast recovering of the tonic level $b$, the excitation effect $(p \cdot s(t) / b)$, which tends to increase the GFP, and the inhibitor effect ( $\left.\int_{0}^{t} \mathrm{e}^{\frac{x-t}{\tau}} \cdot s(x) \cdot y(x) d x\right)$, which tends to decrease the GFP and is the cause of a continuously delayed recovering, with the weight $\mathrm{e}^{\frac{x-t}{\tau}}$. Parameters $a, p, q$ and $\tau$ are named respectively the homeostatic control power, the excitation effect power, the inhibitor effect power and the inhibitor effect delay. All the parameters of the model depend on the individual personality or individual biology and on the type of stimulus. The correct interpretation of the tonic level $b$ is important to be stressed: its value is situational and depends on the individual and the kind of stimulus. The response model provided such as Eq. 2 is fundamental to deduce the bridge model.

Besides, Eq. 2 can be transformed into a system of two coupled differential equations. To do this, let us define the $z(t)$ variable as:

$$
z(t)=\int_{0}^{t} \mathrm{e}^{\frac{x-t}{\tau}} \cdot s(x) \cdot y(x) d x=\mathrm{e}^{-\frac{t}{\tau}} \int_{0}^{t} \mathrm{e}^{\frac{x}{\tau}} \cdot s(x) \cdot y(x) d x
$$

Then, by taking the time derivative of $z(t)$ : 


$$
\begin{gathered}
\left.\frac{d y(t)}{d t}=\begin{array}{c}
a(b-y(t))+\frac{p}{b} s(t)-b \cdot q \cdot z(t) \\
y(0)=y_{0}
\end{array}\right\} \\
\left.\begin{array}{c}
\frac{d z(t)}{d t}=-\frac{z(t)}{\tau}+s(t) \cdot y(t) \\
z(0)=0
\end{array}\right\}
\end{gathered}
$$

Eqs. 1, 4 and 5 define an equivalent mathematical structure of the response model given by Eqs. 1 and 2 , and they are used to obtain in an easy way its numerical solutions.

\section{The bridge model}

In order to deduce the bridge model, the starting point is assuming the invariance principle, i.e., the dynamical response of every biological indicator can be also described by the response model, but with different parameter values. Thus, let us call $E_{i}$ to each one of the three biological indicators, with $1 \leq i \leq 3: E_{1} \equiv C$ (c-fos), $E_{2} \equiv D$ (DRD3) and $E_{3} \equiv G$ (glutamate). In addition, if $E_{l}^{(0)}$ is the corresponding initial value in $t=0$, and $A_{i}, B_{i}, P_{i}, Q_{i}$ and $T_{i}$ are the corresponding parameters, the response model corresponding to the biological indicators can be written as:

$$
\left.\begin{array}{c}
\frac{d E_{i}(t)}{d t}=A_{i}\left(B_{i}-E_{i}(t)\right)+\frac{P_{i}}{B_{i}} S(t)-B_{i} \cdot Q_{i} \cdot \int_{0}^{t} \mathrm{e}^{\frac{x-t}{T_{i}}} \cdot s(x) \cdot E_{i}(x) d x \\
E_{i}(0)=E_{i}^{(0)}
\end{array}\right\}
$$

Note in Eq. 6 that $1 \leq i \leq 3$. From now on wards the subscripts will hold this meaning. In addition, note also that $s(t)$ is the stimulus function, i.e., it is the same than in Eq. 1, which means that it is the same for the three biological indicators and for the GFP. The invariance principle assumes that the influence of the stimulus on the three biological indicators and on the GFP is the same. Therefore, from this hypothesis, $s(t)$ only depends on the individual biology and on the kind of stimulus. As a consequence, $\alpha$ (assimilation rate) and $\beta$ (elimination rate) parameters have the same value for the three biological indicators and for the GFP.

Note again that with the change specified in the following equation:

$$
F_{i}(t)=\int_{0}^{t} \mathrm{e}^{\frac{x-t}{T_{i}}} \cdot s(x) \cdot E_{i}(x) d x=\mathrm{e}^{-\frac{t}{T_{i}}} \int_{0}^{t} \mathrm{e}^{\frac{x}{T_{i}}} \cdot s(x) \cdot E_{i}(x) d x
$$

Eq. 6 becomes a system of two coupled differential equations:

$$
\left.\begin{array}{c}
\frac{d E_{i}(t)}{d t}=A_{i}\left(B_{i}-E_{i}(t)\right)+\frac{P_{i}}{B_{i}} S(t)-B_{i} \cdot Q_{i} \cdot F_{i}(t) \\
E_{i}(0)=E_{l}^{(0)}
\end{array}\right\}
$$

Eqs. 10 and 11 constitute an equivalent mathematical structure of the response model given by Eq. 6, and they are used to obtain in an easy way its numerical solutions. 
To find the mathematical relationship among the biological indicators $\left(E_{i}\right)$, and the GFP $(y)$ and time $(t)$, the starting point is to consider that it can be written as:

$$
E_{i}=E_{i}(t, y)
$$

Taking the time derivative in Eq. 10:

$$
\frac{d E_{i}(t, y)}{d t}=\frac{\partial E_{i}(t, y)}{\partial t}+\frac{\partial E_{i}(t, y) d y}{\partial y \quad d t}
$$

Substituting Eqs. 2 and 6 in Eq. 11, taking into account Eqs, 5 and 9, and considering now that the time function $E_{i}(t)$ is, from Eq. 10, a two-variables function $E_{i}(t, y)$ :

$$
A_{i}\left(B_{i}-E_{i}(t, y)\right)+\frac{P_{i}}{B_{i}} S(t)-B_{i} \cdot Q_{i} \cdot F_{i}(t, y)=\frac{\partial E_{i}(t, y)}{\partial t}+\frac{\partial E_{i}(t, y)}{\partial y}\left(a(b-y)++\frac{p}{b} s(t)-b \cdot q \cdot z(t)\right)
$$

In Eq. 12, $z(t)$ is given by Eq. 3, and $F_{i}(t, y)$, considering Eq. 7, is given by:

$$
F_{i}(t, y)=\int_{0}^{t} \mathrm{e}^{\frac{x-t}{T_{i}}} \cdot s(x) \cdot E_{i}(x, y) d x=\mathrm{e}^{-\frac{t}{T_{i}}} \int_{0}^{t} \mathrm{e}^{\frac{x}{T_{i}}} \cdot s(x) \cdot E_{i}(x, y) d x
$$

Differing from the equation presented in [35] as the bridge model, Eq. 12 is a partial integrodifferential equation, where the integral term is due to Eq. 13, which makes difficult to handle the model mathematically. An alternative way to solve this difficulty is to consider the substitution of Eq. 10 by $E_{i}=E_{i}(t, y, z)$. This approach is held in [41], and the alternative model to Eq. 12 is provided by a set of two coupled first order partial differential equations. However, although an analytical solution seems to be impossible for both approaches, getting a numerical solution presents difficulties due to the artificial dependence on $z$ in $E_{i}(t, y, z)$. The way to avoid the $z$ dependence and to avoid the direct work with a partial integro-differential equation such as Eq. 12 is to convert it into a second order partial differential equation. To do this, the partial time derivative is took in both sides of Eq. 12:

$$
\begin{gathered}
-A_{i} \frac{\partial E_{i}(t, y)}{\partial t}+\frac{P_{i}}{B_{i}} s^{\prime}(t)-B_{i} \cdot Q_{i} \frac{\partial F_{i}(t, y)}{\partial t}=\frac{\partial^{2} E_{i}(t, y)}{\partial t^{2}}+\frac{\partial^{2} E_{i}(t, y)}{\partial t \partial y}\left(a(b-y)+\frac{p}{b} s(t)-b \cdot q \cdot z(t)\right)+\frac{\partial E_{i}(t, y)}{\partial y} \\
\left(\frac{p}{b} s^{\prime}(t)-b \cdot q \cdot z^{\prime}(t)\right)
\end{gathered}
$$

Note from Eq. 5 that $z^{\prime}(t)=-\frac{1}{\tau} z(t)+s(t) \cdot y$, and from Eq. 13:

$$
\frac{\partial F_{i}(t, y)}{\partial t}=-\frac{1}{T_{i}} \mathrm{e}^{-\frac{t}{T_{i}}} \int_{0}^{t} \mathrm{e}^{\frac{x}{T_{i}}} \cdot s(x) \cdot E_{i}(x, y) d x+\mathrm{e}^{-\frac{t}{T_{i}}} \cdot \mathrm{e}^{\frac{t}{T_{i}}} \cdot s(t) \cdot E_{i}(t, y)=-\frac{1}{T_{i}} F_{i}(t, y)+s(t) \cdot E_{i}(t, y)
$$

The substitution of Eqs. 5 and 15 in Eq. 14 provides: 


$$
\begin{aligned}
&-A_{i} \frac{\partial E_{i}(t, y)}{\partial t}+\frac{P_{i}}{B_{i}} s^{\prime}(t)+\frac{B_{i} \cdot Q_{i}}{T_{i}} F_{i}(t, y)- B_{i} \cdot Q_{i} \cdot s(t) \cdot E_{i}(t, y) \\
&=\frac{\partial^{2} E_{i}(t, y)}{\partial t^{2}}+\frac{\partial^{2} E_{i}(t, y)}{\partial t \partial y}\left(a(b-y)+\frac{p}{b} s(t)-b \cdot q \cdot z(t)\right)+ \\
&+\frac{\partial E_{i}(t, y)}{\partial y}\left(\frac{p}{b} s^{\prime}(t)+\frac{b \cdot q}{\tau} \cdot z(t)-b \cdot q \cdot s(t) \cdot y\right)
\end{aligned}
$$

The next step is the elimination of the integral term $B_{i} \cdot Q_{i} \cdot F_{i}(t, y)$ in Eq. 16. First, the term is isolated from Eq. 12:

$$
\begin{aligned}
& \quad B_{i} \cdot Q_{i} \cdot F_{i}(t, y)=A_{i}\left(B_{i}-E_{i}(t, y)\right)+\frac{P_{i}}{B_{i}} S(t)-\frac{\partial E_{i}(t, y)}{\partial t}-\frac{\partial E_{i}(t, y)}{\partial y} \\
& \left(a(b-y)++\frac{p}{b} s(t)-b \cdot q \cdot z(t)\right)
\end{aligned}
$$

Subsequently Eq. 17 is substituted in Eq. 16, and after reorganization:

$$
\begin{gathered}
\frac{\partial^{2} E_{i}(t, y)}{\partial t^{2}}+\left(a(b-y)+\frac{p}{b} s(t)-b \cdot q \cdot z(t)\right) \frac{\partial^{2} E_{i}(t, y)}{\partial t \partial y}+ \\
\left(\frac{p}{b} s^{\prime}(t)+\frac{b \cdot q}{\tau} \cdot z(t)-b \cdot q \cdot s(t) \cdot y+\frac{1}{T_{i}}\left(a(b-y)+\frac{p}{b} s(t)-b \cdot q \cdot z(t)\right)\right) \frac{\partial E_{i}(t, y)}{\partial y}+\left(A+\frac{1}{T_{i}}\right) \frac{\partial E_{i}(t, y)}{\partial t}=\frac{A_{i}}{T_{i}} \\
\left(B_{i}-E_{i}(t, y)\right)-B_{i} \cdot Q_{i} \cdot s(t) \cdot E_{i}(t, y)+\frac{P_{i}}{T_{i} \cdot B_{i}} S(t)+\frac{P_{i}}{B_{i}} S^{\prime}(t)
\end{gathered}
$$

Eq. (18) must be completed with the boundary conditions:

$$
\begin{aligned}
& E_{i}(0, y)=E_{l}^{(0)} \\
& \frac{\partial E_{i}}{\partial t}(0, y)=A_{i}\left(B_{i}-E_{l}^{(0)}\right)
\end{aligned}
$$

Eqs. 18,19 and 20 provide the new version of the bridge model. Note that Eq. 19 provides the initial condition for each one of the biological indicators, while Eq. 20 is obtained from Eq. 6 due to $s(t)=0$ before the drug consumption. For computation purposes in Eq. 18, $s(t)$ is the time function given by Eq. 1 and $s^{\prime}(t)$ its time derivative, while $z(t)$ is considered a time function obtained from the numerical solution of the system given by Eqs 4 and 5. Note that from Eq. 3, the $z(t)$ term in Eq. 18 considers that its solutions assume all the past history of the GFP since the stimulus is provided.

\section{The experimental designs}

The application case considered in order to validate the response and bridge models is put in practice for two subjects. A previous $\mathrm{AB}$ pseudo-experimental design is set up for Case 1 and a subsequent $\mathrm{ABC}$ experimental design is set up for Case 2. In fact, the design $\mathrm{AB}$ is not an experimental design, but an exploratory case study. Once positive results have been obtained that inform about a change in the scores of the scales of personality when taking $20 \mathrm{mg}$ of methylphenidate compared with the base-line for Case 1, the authors decided to repeat the experiment with another subject, Case 2, but this time with an experimental design of unique case 
with three phases: A, B and C, where Phase A is again the base-line, Phase B with taking $20 \mathrm{mg}$ of methylphenidate, and Phase $\mathrm{C}$ with taking $40 \mathrm{mg}$ of methylphenidate.

The participants (Case 1 and Case 2) are two males with 50 and 52 years old. They are two voluntaries of the university teaching staff. The instruments are the Five-Adjective Scale of the General Factor of Personality (GFP-FAS) [14, 15]. The 5 adjectives are: adventurous, daring, enthusiastic, merry and bored. Each adjective is evaluated by the subjects from 0 to 5, thus the scale of the GFP is $y \in[0,25]$.

The biological analyses to obtain the referred biological indicators are of two kinds. To obtain the c-fos and DRD3 samples, the lymphocytes of the blood samples were isolated by density centrifugation on Lymphoprep. Finally, an automated mass spectrometry platform (Sequenom, MassARRAY Quantitative Gene Expression) was used for quantification of the c-fos and the DRD3 concentrations in lymphocytes. $\beta$-actin was used as internal standard RNA. In addition, a mass spectrometer was used to obtain the glutamate level in blood. C-fos and DRD3 are measured by their molar concentration (mc) in lymphocytes in blood. The c-fos measures are used with a scale multiplied by $10^{18} \mathrm{mc}$ and the DRD3 measures are used with a scale multiplied by $10^{21} \mathrm{mc}$. With these scales, the c-fos $\left(E_{1} \equiv C\right)$ and DRD3 $\left(E_{2} \equiv D\right)$ concentrations vary in the interval $C, D \in[0,100]$. The glutamate $E_{3} \equiv G$ is measured by the direct molar concentration (mc) in blood and it is used with a scale multiplied by $10^{18} \mathrm{mc}$. With this scale, the glutamate concentration varies in the interval $G \in[0,60]$.

In all phases participants fill out the GFP-FAS each fifteen minutes (17 registers each phase) and peripheral blood samples are obtained each one hour ( 5 samples each phase). In addition the experimental conditions take place in a hospital room a morning with an empty stomach, with no drug consumption and in resting and isolated atmosphere, trying to minimize the external stimuli in Phases A and also to maximize the effect of methylphenidate in Phases B and C.

The $\mathrm{AB}$ pseudo-experimental design is set up for Case 1. Phase $\mathrm{A}$ is the base-line, without treatment. A week later, in Phase B, Case 1 receives a dose of $20 \mathrm{mg}$ of methylphenidate immediately after filling out the first list of the GFP-FAS and the initial blood sample is obtained. In the following, Case 1 fills out 16 lists of the GFP-FAS, one each fifteen minutes, and a blood sample is obtained each hour along 4 hours.

One week later, the ABC experimental design is set up for Case 2. Phases A and B of Case 2 are set up in the same way than for Case 1, with Phases A and B separated for one week. One week later than Phase $\mathrm{B}$, in Phase $\mathrm{C}$ Case 2 receives a dose of $40 \mathrm{mg}$ of methylphenidate immediately after filling out the first list of the GFP-FAS and the initial blood sample is obtained. In the following, Case 2 fills out 16 lists of the GFP-FAS, one each fifteen minutes, and a blood sample is obtained each hour along 4 hours.

Observe that for Case 1 in Phase B and for Case 2 in Phases B and C, each one of the measures before consuming represent the initial conditions for the response model, which is evaluated with the initial condition plus the 16 lists of the GFP-FAS. Also the response model is evaluated with the initial condition plus the 4 blood samples for the biological indicators. In addition, the bridge model can only be evaluated with those outcomes that coincide in time, i.e., with the outcomes obtained each one hour. The results of both experiments are presented in the following sections in tables and graphics, in the context of the response and bridge models validation.

\section{Validation of the response model}


The aim of this section is to validate the response model by calibration for both the GFP and the three biological indicators for both experimental designs.

The calibration method consists in comparing the experimental data obtained from the different lists of scores with the theoretical values provided by the response model. On a hand, the experimental GFP-FAS scores are compared with the theoretical outcomes provided by the $y(t)$ model variable given by Eqs. 1 and 2. On the other hand, the experimental biological scores are compared with the theoretical outcomes provided by the $E_{i}(t)$ model variables given by Eqs. 1 and 6.

To obtain the theoretical outcomes, Eqs. 2 and 6 have been programmed in $\mathrm{C}++$ language, solving the equivalent differential equations, respectively, Eqs. 4 and 5 for Eq. 2, and Eqs. 8 and 9 for Eq. 6, by the 4th Runge-Kutta method. The $\mathrm{C}++$ program includes the way to compare the experimental scores and the theoretical outcomes. It consists in minimizing the quadratic sum of both sets of data by generating random numbers. Observe in addition that in the method development the initial value of Eq. $4, y_{0}$, and of Eq. $8, E_{l}^{(0)}$, are known because they are the corresponding values before the methylphenidate stimulus is implemented.

Observe that the validation has sense when the methylphenidate stimulus is provided, i.e., for Phase $\mathrm{B}$ in the pseudo-experimental design $\mathrm{AB}$, and for Phases $\mathrm{B}$ and $\mathrm{C}$ in the experimental design $\mathrm{ABC}$. In addition, the goodness of the validation is here provided by: (a) the visual inspection of the Figure 1 that represent jointly the experimental and the theoretical outcomes, in the order: GFP, c-fos, DRD3 and glutamate; (b) for the fitting degree of both data sets, here computed by the determination coefficient $\left(\mathrm{R}^{2}\right)$, which varies in the interval [0,1]: the closer to the unit the determination coefficient is the better fitting degree of both data sets.

Observe also that Phases A of both experimental designs play the role of a control base-line: the observable differences between Phases A and Phases B and C (where the methylphenidate stimulus is provided) indicate that the stimulus produces an appreciable change.

Let us start with Case 1, corresponding to the pseudo-experimental design AB. Phase A of Case 1 is represented in Fig. 1 (a)-(d). Note that for this case, the responses to the quietness and isolation conditions of Phase A work as control base-line. On a hand, the experimental values change around a constant value such as it happens in Fig. 1(a) for the GFP or in Fig. 1(b) for the c-fos. On the other hand, Fig. 1(c) shows a slight inverted U-shape for the DRD3, and Fig. 1(d) a more stressed U-shape for the glutamate. However, the trends are different to those present in Phase B. In fact, besides, Phase B of Case 1 is represented in Figs. (f) - (i) as a consequence of a dose of $20 \mathrm{mg}$. Note that both the GFP (Fig. 1(f)) and the c-fos (Fig. 1(g)) present a stressed inverted U-shape dynamics, while the DRD3 dynamics (Fig. 1(h)) is oscillatory and the glutamate dynamics presents a slight inverted U-shape dynamics (Fig. 1(i)). All determination coefficients range between 0.85 and 0.97. Thus, the response model can be considered validated for Phase B of Case 1.

In order to validate with Case 2, corresponding to the experimental design ABC and Phase A of Case 2 is represented in Fig. 1 (j)-(m). Phase B of Case 2 is shown in Figs. Fig. 1 (o)-(r), illustrates the GFP, c-fos, DRD3 and glutamate dynamics as a consequence of a dose of $20 \mathrm{mg}$ of 
methylphenidate we proceed analogously to case 1 (using the same arguments). Let us remark that all determination coefficients range between 0.85 and 0.99 . The response model can be considered validated for Phase B of Case 2. Similar arguments are used to validate the Phase C of Case 2, Fig. 1(s)-(v), that provides determination coefficients range between 0.82 and 0.99 .

The corresponding optimal values of the model parameters for Phase B of Case 1, for Phase B Case 2 and Phase $\mathrm{C}$ of Case 2 are presented in Table 1. Note that those parameters corresponding to the stimulus equation have the same value for the GFP and for the three biological indicators.

\section{Validation of the bridge model}

The theoretical values provided by the bridge model, $E_{i}(t, y)$, are given by the numerical solutions of Eqs.18, 19 and 20, with the optimal parameter values obtained in the calibration process of the response model (Table 1). These numerical solutions have been obtained using the NDSolve function of MATHEMATICA 10.4. On a hand, the validation of the bridge model is provided by visual inspection: the joined representation of the experimental scores and the theoretical values $E_{i}(t, y)$ of the biological indicators versus the experimental values of the GFP. On other hand, the validation is supported by the corresponding determination coefficients of both sets of data. Note that this validation has only sense for Phase B of Case 1 and for Phases B and C of Case 2.

Consider Phase B of Case 1 and the corresponding optimal values of Table 1 to obtain the theoretical values by using the bridge model. Fig. 2 (a)-(d) present the joined results of the experimental biological indicators and theoretical values versus the GFP experimental values. Note that, both the visual inspection of the figures and the determination coefficients that range between $\mathrm{R}^{2}=0.85$ and $\mathrm{R}^{2}=0.97$, provide the validation of the bridge model for Phase $\mathrm{B}$ of Case 1 . Similar arguments can be used to validate the bridge model for the Phase B of Case 2 with determination coefficients that range between $\mathrm{R}^{2}=0.85$ and $\mathrm{R}^{2}=0.99$ (see Fig. 2(e)-(g)) and Phase $\mathrm{C}$ of Case 2 determination coefficients that range between $\mathrm{R}^{2}=0.82$ and $\mathrm{R}^{2}=0.99$ (see Fig. 2(h)$(\mathrm{k}))$.

The general conclusion of this section is that the bridge model can be considered validated from the outcomes of both experimental designs.

\section{Conclusions and discussion}

The response model has been validated by calibration in the context of a previous (pilot) AB experiment and a subsequent $\mathrm{ABC}$ experimental design. As a consequence of getting the optimal parameter values for the response model, the presented bridge model has also been validated. Thus, it is confirmed that the GFP and the three biological indicators, c-fos, DRD3 and glutamate, vary jointly in response to a dose of a stimulating drug (methylphenidate). In addition, the validation of the bridge model in the context of both experimental designs provides the co-evolution of the GFP (mind) and the three biological indicators, c-fos, DRD3 and glutamate, (body). However, it seems obvious that future experimental designs might consider more subjects and more phases, due to the present study is centered on individuals, not in groups. The experimental designs of groups 
would provide statistical significations, which would increase the consistency of the response and bridge models. Besides, other kinds of stimuli should be considered in alternative experimental designs, such as caffeine, alcohol, self-regulation therapy, etc., which would also consolidate the value of response and bridge models to study the body-mind problem.

In addition, let us stress that the bridge model is consequence of the assumption of the mathematical invariance principle, which determines the same mathematical structure to describe the dynamics of the GFP and the three biological indicators. Thus, here works the assumption of the general applicability in behavioral sciences of the differential models used by physics and other disciplines related with applied mathematics. This assumption has been demonstrated in the last centuries in science as a method to study successfully dynamics, complexity and nonlinearity. In fact, both the response and the bridge models have been demonstrated that are two successful mathematical tools to study the co-evolution of the GFP and the three biological indicators, as a consequence of a stimulus, such as a single dose of methylphenidate. Then, both models provide a new perspective to study the body-mind problem.

The new perspective has to be framed in practical applications in future. In fact, a concrete application of the bridge model would consist in being used to simulate changes in biology from the self-regulation therapy: those changes that would steer biology towards suitable dynamical states for the individual personality.

Note however that the present investigation is based on short term dynamics described by the response model. But the response model presented in [23] provides predictions at long term. A corresponding bridge model deduced under the invariance principle from the response model of [23] would be suitable to simulate changes in biology and personality at long term. This further bridge model would provide a tool to solve, for instance, problems of addiction from the double behavioral and biological perspective.

It is over understood by the authors that a definitive solution of the body-mind problem must consider the overall biology that underlies personality, which involves much more biological indicators than those here presented and their dynamical interrelationships, as well as their interaction with the stress system through the nervous system. In other words, a unified theory of the three levels of personality description: biological, physiological and psychological ones.

\section{References}

[1] S. Amigó, La teoría del rasgo único de personalidad. Hacia una teoría unificada del cerebro y la conducta (The unique-trait personality theory. Towards a unified theory of brain and conduct), Ed. Universitat Politècnica de València, 2005.

[2] S. Amigó, A. Caselles, J.C. Micó, The General Factor of Personality Questionnaire (GFPQ): Only one factor to understand the personality?, Span. J. Psychol. (2010) 5-17.

[3] J.P. Rushton, T.A. Bons, J. Ando, Y.-M. Hur, P. Irwing, P.A. Vernon, K. V. Petrides, C. Barbaranelli, A General Factor of Personality From Multitrait-Multimethod Data and Cross-National Twins, Twin Res. Hum. Genet. 12 (2009) 356-365. doi:10.1375/twin.12.4.356.

[4] J.P. Rushton, T.A. Bons, Y.-M. Hur, The genetics and evolution of the general factor of personality, J. Res. Pers. 42 (2008) 1173-1185. doi:10.1016/j.jrp.2008.03.002.

[5] J.P. Rushton, P. Irwing, A General Factor of Personality (GFP) from two meta-analyses of the Big Five: and, Pers. Individ. Dif. 45 (2008) 679-683. doi:10.1016/j.paid.2008.07.015.

[6] J.P. Rushton, P. Irwing, A general factor of personality in the Comrey Personality Scales, the Minnesota Multiphasic Personality Inventory-2, and the Multicultural Personality Questionnaire, Pers. Individ. Dif. 46 (2009) 437-442. doi:10.1016/j.paid.2008.11.015. 
[7] J.P. Rushton, P. Irwing, A General Factor of Personality in 16 sets of the Big Five, the Guilford-Zimmerman Temperament Survey, the California Psychological Inventory, and the Temperament and Character Inventory, Pers. Individ. Dif. 47 (2009) 558-564. doi:10.1016/j.paid.2009.05.009.

[8] J.P. Rushton, P. Irwing, A General Factor of Personality (GFP) from the Multidimensional Personality Questionnaire, Pers. Individ. Dif. 47 (2009) 571-576. doi:10.1016/j.paid.2009.05.011.

[9] J.P. Rushton, P. Irwing, A General Factor of Personality in the Millon Clinical Multiaxial Inventory-III, the Dimensional Assessment of Personality Pathology, and the Personality Assessment Inventory, J. Res. Pers. 43 (2009) 1091-1095. doi:10.1016/j.jrp.2009.06.002.

[10] L. Veselka, J.A. Schermer, K. V. Petrides, L.F. Cherkas, T.D. Spector, P.A. Vernon, A General Factor of Personality: Evidence from the HEXACO Model and a Measure of Trait Emotional Intelligence, Twin Res. Hum. Genet. 12 (2009) 420-424. doi:10.1375/twin.12.5.420.

[11] L. Veselka, J.A. Schermer, K. V. Petrides, P.A. Vernon, Evidence for a Heritable General Factor of Personality in Two Studies, Twin Res. Hum. Genet. 12 (2009) 254-260. doi:10.1375/twin.12.3.254.

[12] J.A. Schermer, P.A. Vernon, The correlation between general intelligence (g), a general factor of personality (GFP), and social desirability, Pers. Individ. Dif. 48 (2010) 187-189. doi:10.1016/j.paid.2009.10.003.

[13] S. Erdle, P. Irwing, J.P. Rushton, J. Park, The General Factor of Personality and its relation to Self-Esteem in 628,640 Internet respondents, Pers. Individ. Dif. 48 (2010) 343-346. doi:10.1016/j.paid.2009.09.004.

[14] S. Amigó, J.C. Micó, A. Caselles, Adjective scale of the unique personality trait: measure of personality as an overall and complete system, in: Proc. 7th Congr. Eur. Syst. Union, Lisboa, 2008.

[15] S. Amigó, J.C. Micó, A. Caselles, Five adjectives to explain the whole personality: a brief scale of personality, Rev. Int. Sist. (2009) 41-43. http://www.uv.es/caselles/.

[16] S. Amigó, A. Caselles, J.C. Micó, A dynamic extraversion model. The brain's response to a single dose of a stimulant drug, Br. J. Math. Stat. Psychol. 61 (2008) 211-231. doi:10.1348/000711007X185514.

[17] R.L. Solomon, J.D. Corbit, An opponent-process theory of motivation: I. Temporal dynamics of affect, Psychol. Rev. 81 (1974) 119-145. doi:10.1037/h0036128.

[18] G.F. Koob, Drug Abuse: Hedonic Homeostatic Dysregulation, Science (80-. ). 278 (1997) 52-58. doi:10.1126/science.278.5335.52.

[19] G. Koob, Drug Addiction, Dysregulation of Reward, and Allostasis, Neuropsychopharmacology. 24 (2001) 97-129. doi:10.1016/S0893-133X(00)00195-0.

[20] S. Grossberg, The imbalanced brain: from normal behavior to schizophrenia, Biol. Psychiatry. 48 (2000) 81-98. doi:10.1016/S0006-3223(00)00903-3.

[21] A. Caselles, J.C. Mico, S. Amigo, Dynamics of the General Factor of Personality in Response to a Single Dose of Caffeine, Span. J. Psychol. 14 (2011) 675-692. doi:10.5209/rev_SJOP.2011.v14.n2.16.

[22] J.C. Micó, S. Amigó, A. Caselles, Changing the General Factor of Personality and the c-fos Gene Expression with Methylphenidate and Self-Regulation Therapy, Span. J. Psychol. 15 (2012) 850-867. doi:10.5209/rev_SJOP.2012.v15.n2.38896.

[23] A. Caselles, J.C. Micó, S. Amigó, Cocaine addiction and personality: A mathematical model, Br. J. Math. Stat. Psychol. 63 (2010) 449-480. doi:10.1348/000711009X470768.

[24] M. Pompeiano, C. Cirelli, P. Arrighi, G. Tononi, c-Fos expression during wakefulness and sleep, Neurophysiol. Clin. Neurophysiol. 25 (1995) 329-341. doi:10.1016/0987-7053(96)84906-9.

[25] S.J. Meador-Wooddruff, J. H., Mansour, A., Saul, J., \& Watson, Neuroanalomical distribution of dopamine receptor messenger RNAs, in: H.B. Niznik (Ed.), Dopamine Recept. Transp., Marcel Dekker, New York, 1994: pp. 401-415.

[26] B. Levant, The D 3 Dopamine Receptor : Neurobiology and Potential Clinical Relevance, Pharmacol. Rev. 49 (1997) 231-252.

[27] C. Czermak, M. Lehofer, H. Renger, E.M. Wagner, L. Lemonis, A. Rohrhofer, K. Schauenstein, P.M. Liebmann, Dopamine receptor D3 mRNA expression in human lymphocytes is negatively correlated with the personality trait of persistence, J. Neuroimmunol. 150 (2004) 145-149. doi:10.1016/j.jneuroim.2004.01.009.

[28] S. Caine, G. Koob, Modulation of cocaine self-administration in the rat through D-3 dopamine receptors, Science (80-. ). 260 (1993) 1814-1816. doi:10.1126/science.8099761.

[29] B.J. Everitt, P. Sokoloff, M. Pilla, S. Perachon, F. Sautel, F. Garrido, A. Mann, C.G. Wermuth, J.-C. 
Schwartz, Selective inhibition of cocaine-seeking behavior by a partial dopamine D3 receptor agonist, Nature. 400 (1999) 371-375. doi:10.1038/22560.

[30] S. Amigó, A. Caselles, J.C. Micó, Self-Regulation Therapy to Reproduce Drug Effects: A Suggestion Technique to Change Personality and the DRD3 Gene Expression, Int. J. Clin. Exp. Hypn. 61 (2013) 282304. doi:10.1080/00207144.2013.784094.

[31] J.. Amigó, S., Caselles, A., Micó, J.C., García, Dynamics of the unique trait of personality: blood's glutamate in response to methylphenidate and conditioning, Rev. Int. Sist. 16 (2009) 35-40.

[32] N.D. Volkow, L. Chang, G.-J. Wang, J.S. Fowler, Y.-S. Ding, M. Sedler, J. Logan, D. Franceschi, J. Gatley, R. Hitzemann, A. Gifford, C. Wong, N. Pappas, Low Level of Brain Dopamine D 2 Receptors in Methamphetamine Abusers: Association With Metabolism in the Orbitofrontal Cortex, Am. J. Psychiatry. 158 (2001) 2015-2021. doi:10.1176/appi.ajp.158.12.2015.

[33] N. Volkow, Role of dopamine in the therapeutic and reinforcing effects of methylphenidate in humans: results from imaging studies, Eur. Neuropsychopharmacol. 12 (2002) 557-566. http://linkinghub.elsevier.com/retrieve/pii/S0924977X02001049.

[34] J.C. Micó, A. Caselles, S. Amigó, A. Cotolí, M.T. Sanz, A Mathematical Approach to the Body-Mind Problem from a System Personality Theory (A Systems Approach to the Body-Mind Problem), Syst. Res. Behav. Sci. 30 (2013) 735-749. doi:10.1002/sres.2241.

[35] J.C. Micó, S. Amigó, A. Caselles, From the Big Five to the General Factor of Personality: a Dynamic Approach, Span. J. Psychol. 17 (2014) E74. doi:10.1017/sjp.2014.71. 


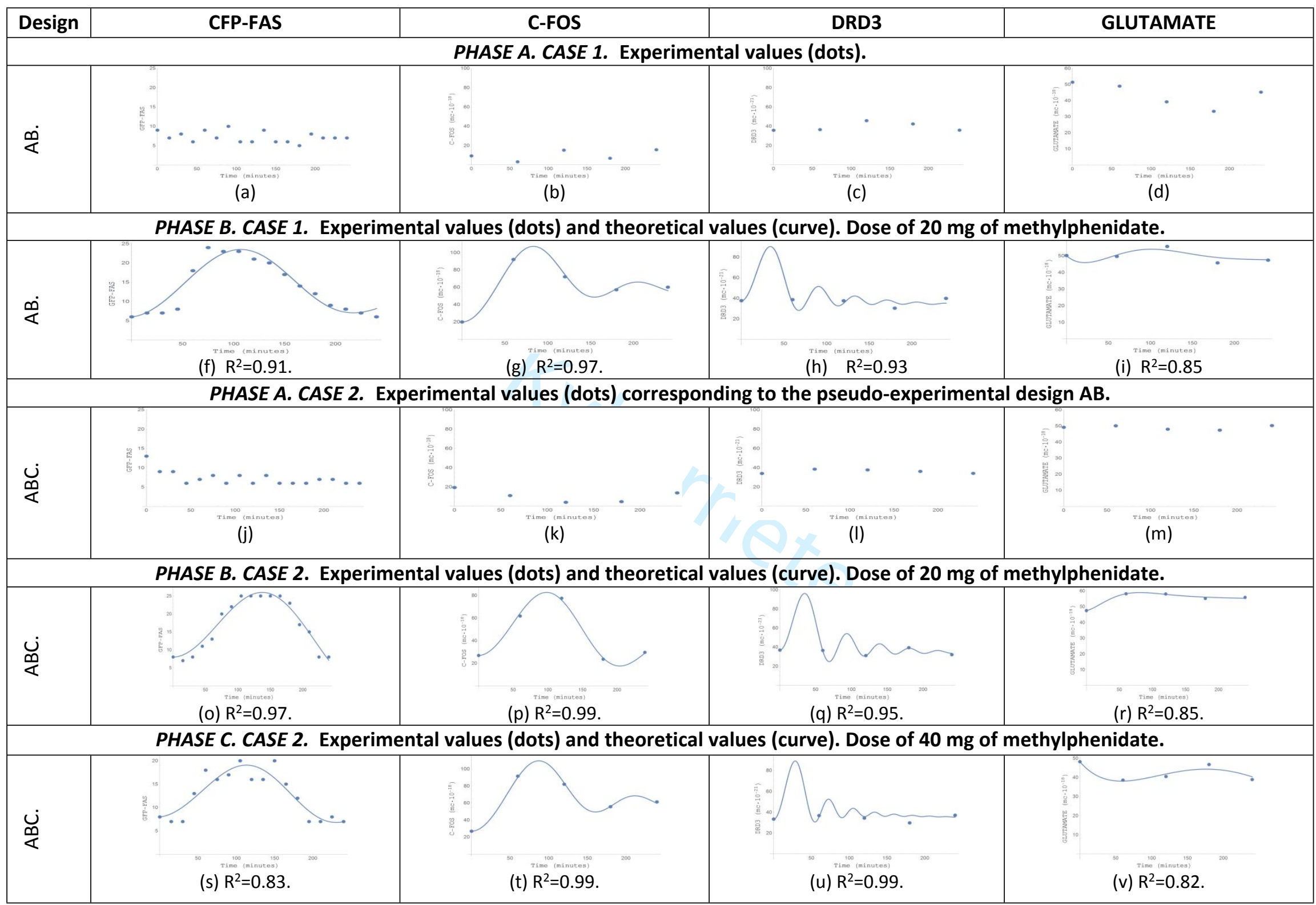

Figure 1 Validation of the response and bridge model. 


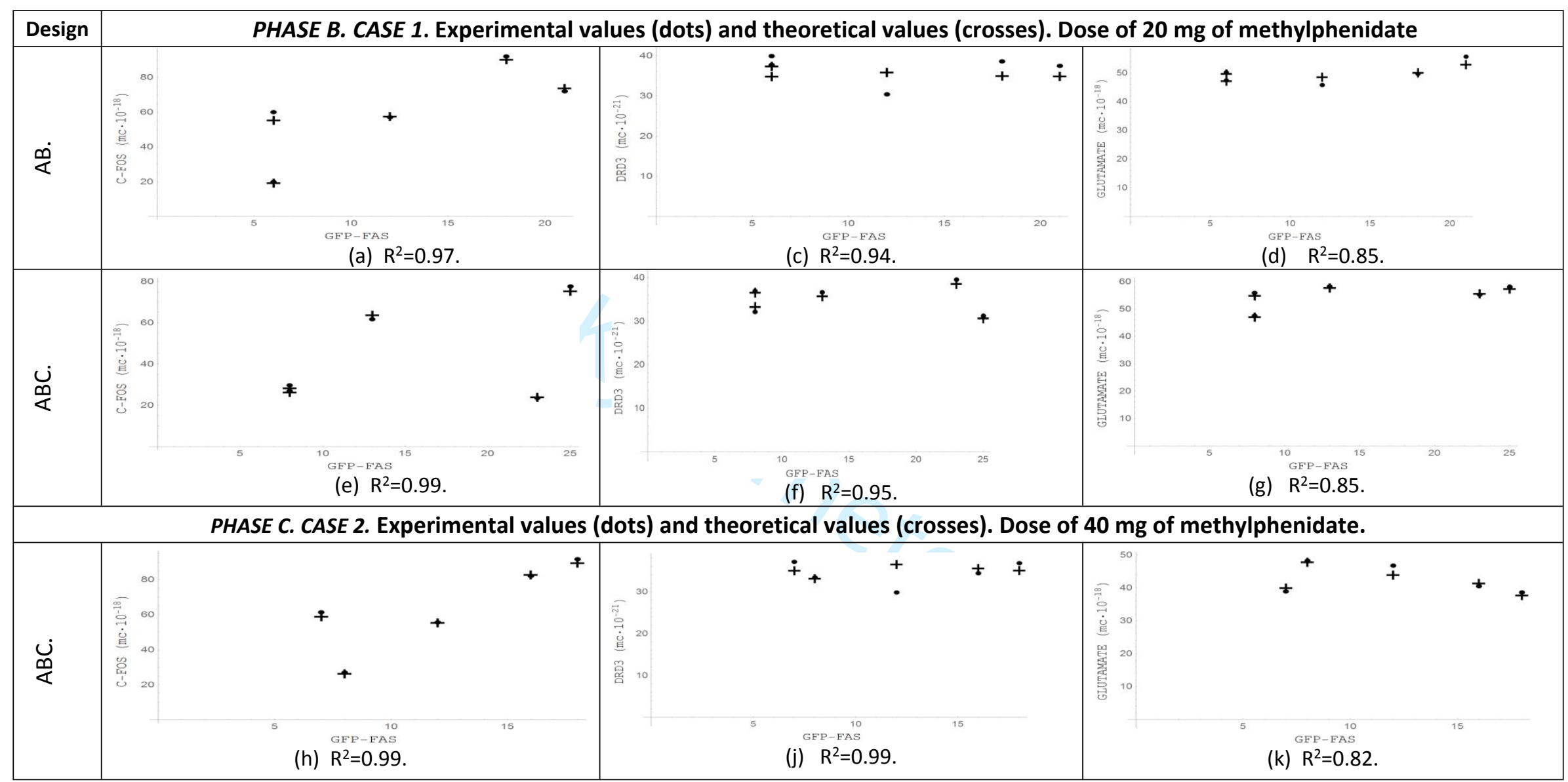

Figure 2 Comparasion between CFP and FAS. Different cases and doses 
Design AB. PHASE B. CASE 1. Dose of $20 \mathrm{mg}$ of methylphenidate.

\begin{tabular}{|c|c|c|c|c|}
\hline \multicolumn{5}{|c|}{ Design AB. PHASE B. CASE 1. Dose of $20 \mathrm{mg}$ of methylphenidate. } \\
\hline Parameters & GFP dynamics & C-FOS & DRD3 & GLUTAMATE \\
\hline Methylphenidate dose (M) & $2.0000 \mathrm{e}+001$ & $2.0000 e+001$ & $2.0000 \mathrm{e}+001$ & $2.0000 e+001$ \\
\hline Inhibitor effect delay $\left(T_{i}\right)$ & $1.0213 e+002$ & $4.3812 \mathrm{e}+001$ & $3.0735 e+001$ & $3.6923 e+001$ \\
\hline Assimilation rate $(\alpha)$ & $3.2861 \mathrm{e}-003$ & $3.2861 \mathrm{e}-003$ & $3.2861 \mathrm{e}-003$ & $3.2861 \mathrm{e}-003$ \\
\hline Distribution rate $(\beta)$ & $8.8380 \mathrm{e}-004$ & $8.8380 \mathrm{e}-004$ & $8.8380 \mathrm{e}-004$ & $8.8380 \mathrm{e}-004$ \\
\hline Homeostatic control power $\left(A_{i}\right)$ & $4.9064 \mathrm{e}-003$ & $6.3018 \mathrm{e}-004$ & $4.0129 \mathrm{e}-003$ & $1.7164 \mathrm{e}-002$ \\
\hline Tonic level $\left(B_{i}\right)$ & $1.0924 \mathrm{e}+001$ & $1.4871 \mathrm{e}+001$ & $1.6519 e+001$ & $2.3570 \mathrm{e}+001$ \\
\hline Excitation effect power $(\mathrm{P})$ & $1.3322 \mathrm{e}+000$ & $1.4456 \mathrm{e}+001$ & $6.3232 \mathrm{e}+001$ & $8.5710 \mathrm{e}+000$ \\
\hline Inhibitor effect power $\left(Q_{i}\right)$ & $1.2676 \mathrm{e}-005$ & $2.8545 \mathrm{e}-005$ & $2.3233 e-004$ & $8.4998 \mathrm{e}-006$ \\
\hline \multicolumn{5}{|c|}{ Design ABC. PHASE B. CASE 2. Dose of $20 \mathrm{mg}$ of methylphenidate. } \\
\hline & GFP dynamics & C-FOS & DRD3 & GLUTAMATE \\
\hline Methylphenidate dose (M) & $2.0000 e+001$ & $2.0000 e+001$ & $2.0000 \mathrm{e}+001$ & $2.0000 e+001$ \\
\hline Inhibitor effect delay (Ti) & $1.7473 e+002$ & $8.2863 e+001$ & $3.1139 e+001$ & $1.1166 \mathrm{e}+001$ \\
\hline Assimilation rate $(\alpha)$ & $5.3711 \mathrm{e}-003$ & $5.3711 \mathrm{e}-003$ & $5.3711 \mathrm{e}-003$ & $5.3711 \mathrm{e}-003$ \\
\hline Distribution rate $(\beta)$ & $1.5732 \mathrm{e}-003$ & $1.5732 \mathrm{e}-003$ & $1.5732 \mathrm{e}-003$ & $1.5732 \mathrm{e}-003$ \\
\hline Homeostatic control power (Ai) & $2.6764 \mathrm{e}-004$ & 0 & $2.8734 \mathrm{e}-004$ & $1.2631 \mathrm{e}-002$ \\
\hline Tonic level (Bi) & $4.6680 e+000$ & $2.0365 e+001$ & $1.8213 e+001$ & $5.3462 e+001$ \\
\hline Excitation effect power (P) & $2.4243 e-001$ & $6.1950 e+000$ & $4.4131 \mathrm{e}+001$ & $1.1024 \mathrm{e}+001$ \\
\hline Inhibitor effect power (Qi) & $8.4485 \mathrm{e}-006$ & $5.7396 \mathrm{e}-006$ & $1.2699 \mathrm{e}-004$ & $6.2781 \mathrm{e}-006$ \\
\hline \multicolumn{5}{|c|}{ Design ABC. PHASE C. CASE 2. Dose of $40 \mathrm{mg}$ of methylphenidate. } \\
\hline & GFP dynamics & C-FOS & DRD3 & GLUTAMATE \\
\hline Methylphenidate dose (M) & $4.0000 e+001$ & $4.0000 e+001$ & $4.0000 e+001$ & $4.0000 \mathrm{e}+001$ \\
\hline Inhibitor effect delay (Ti) & $9.1556 \mathrm{e}+001$ & $4.7736 e+001$ & $2.4158 e+001$ & $9.8056 \mathrm{e}+002$ \\
\hline Assimilation rate $(\alpha)$ & $1.0778 \mathrm{e}-003$ & $1.0778 \mathrm{e}-003$ & $1.0778 \mathrm{e}-003$ & $1.0778 \mathrm{e}-003$ \\
\hline Distribution rate $(\beta)$ & 7.4257e-004 & 7.4257e-004 & 7.4257e-004 & 7.4257e-004 \\
\hline Homeostatic control power (Ai) & $1.7457 \mathrm{e}-003$ & 0 & 5.3887e-003 & $1.4485 \mathrm{e}-002$ \\
\hline Tonic level (Bi) & $1.6158 \mathrm{e}+001$ & $2.5438 \mathrm{e}+001$ & $8.4389 e+000$ & $1.8165 \mathrm{e}+001$ \\
\hline Excitation effect power $(\mathrm{P})$ & $1.6580 \mathrm{e}+000$ & $3.1705 e+001$ & $7.2391 \mathrm{e}+001$ & $2.7192 \mathrm{e}+000$ \\
\hline Inhibitor effect power (Qi) & $9.4120 \mathrm{e}-006$ & $2.0085 \mathrm{e}-005$ & $1.2778 \mathrm{e}-003$ & $1.3752 \mathrm{e}-006$ \\
\hline
\end{tabular}

Table 1. Optimal values of the response model for different cases. 